\title{
A 1998-2013 climatology of Kyushu, Japan: seasonal variations of stability and rainfall
}

\author{
$\operatorname{AUTHOR}(\mathrm{S})$ :
}

Poulidis, Alexandros P.; Takemi, Tetsuya

\section{CITATION:}

Poulidis, Alexandros P. ...[et al]. A 1998-2013 climatology of Kyushu, Japan: seasonal variations of stability and rainfall. International Journal of Climatology 2017, 37(4): 18431858

ISSUE DATE:

2017-03-30

URL:

http://hdl.handle.net/2433/219135

\section{RIGHT:}

This is the accepted version of the following article: Poulidis, A. P. and Takemi, T. (2017). A 1998-2013 climatology of Kyushu, Japan: seasonal variations of stability and rainfall. Int. J. Climatol., 37: 1843-1858], which has been published in final form at http://doi.org/10.1002/cpe.3522. This article may be used for non-commercial purposes in accordance with Wiley Terms and Conditions for Self-Archiving;; The full-text file will be made open to the public on 14 MAR 2018 in accordance with publisher's 'Terms and Conditions for Self-Archiving'.; この論文は出版社版でありません。引用の際に は出版社版をご磼認じ利用ください。; This is not the published version. Please cite only the published version. 
5 Short title: A 1998-2013 sounding and rainfall climatology of Kyushu, Japan

6 Keywords: rawinsonde, rainfall, climatology, rainy season, Japan, Kyushu

7 Corresponding author: A. P. Poulidis, Disaster Prevention Research Institute,

8 Kyoto University, Gokasho, Uji, 611-0011, Japan (a.poulidis@storm.dpri.kyoto-u.ac.jp)

9 Affiliations: ${ }^{1}$ Disaster Prevention Research Institute, Kyoto University 


\section{Abstract}

The seasonal variation of the atmospheric structure, vertical shear, stability and rainfall distribution over the island of Kyushu, southern Japan, is studied using 16 years of observational data, from 1998 to 2013. Over 20000 twice-daily rawinsonde observations from the cities of Kagoshima (southern Kyushu) and Fukuoka (northern Kyushu) are utilised along with daily precipitation data from 120 Japan Meteorological Agency stations located across the island. Understanding the local atmospheric circulation and climatological behaviour of the island is important both locally due to the island's large population and regionally, due to its position in relation to the tracks of typhoons generated annually over the Pacific ocean and make landfall here, the rainy season associated with the Asian monsoon, and the large number of active volcanoes located on or near the island, emitting volcanic gases and ash on a daily basis.

Using a categorisation based on convective available potential energy and precipitable water, three sounding categories are distinguished, described using the origins of the air masses involved, as seen from trajectory modelling: Continental (Dry), Oceanic (Moist/Unstable), and Mixed (Moist/Stable). Mean soundings for each category are examined, along with information on their annual and seasonal variability. Each sounding category is linked with a rainfall response: low amounts of rainfall, heavy convective rainfall, and heavy, non-convective rainfall respectively. Despite the large difference in the potential for heavy rainfall rates, average daily rainfall rate is similar for the two moist categories, but peak rainfall rates for convective rainfall are twice as large as those for non-convective. Despite the simplicity of the criteria, the 
three sounding categories are statistically robust and exhibit a relatively small amount of variability. The monthly combination of the sounding categories is shown to be a deciding factor in the seasonal variation of the atmospheric circulation, weather, and precipitation over the island. 
39

40

41

42

4

44

45

46

47

48

\section{Introduction}

Seasonal variability is a well known characteristic of Japanese climate, ingrained in Japanese culture with innumerable mentions of the "four seasons" (shiki) in Japanese literature and arts (Ackermann, 1997). This seasonality stems from the combination of several stationary weather systems and fronts (Uvo et al., 2001). In the south of Japan, during the winter season (December, January, February or DJF in figures) air flow towards Japan is mainly controlled by the stationary Siberian High and Aleutian Low systems leading to low amounts of precipitation (Kazaoka and Kida, 2006). In spring (MAM) the weather is mainly forced by transient mid-latitude synoptic cyclones, while in late spring and early to mid-summer (JJA) the weather is mainly characterised by the East Asian rainy season. This is caused by the Baiu/Meiyu stationary front (Wang and Ho, 2002): Dry continental air masses are mixed with moist air forced from the Pacific brought by the Pacific High resulting to large amounts of rainfall between May and July. Towards the end of the summer and throughout the majority of autumn (SON) the weather is largely characterised by the Summer Monsoon, typhoons, and other tropical low pressure systems (Gray, 1968). Although these are typical elements of the Japanese climate in general, different parts of Japan are affected to differing degrees as the Japanese islands stretch between longitudes of $24^{\circ}-45^{\circ} \mathrm{N}$.

The island of Kyushu is the southernmost of the four main islands (approximately $131^{\circ} \mathrm{E}$ and $33^{\circ} \mathrm{N}$; Fig. 1a). It has the second highest population density (332.38 $\mathrm{km}^{-2}$ ) after the main island of Honshu. The topography of the island is complex, characterised by the numerous peaks of the Kyushu mountains, the highest peak 
being Mount Nakadake of the Kuju mountains at $1791 \mathrm{~m}$. Kyushu is also home to a number of active volcanoes, such as Mounts Unzen, Sakurajima, Aso and Kirishima.

Most Japanese islands are prone to natural hazards with earthquakes, volcanic eruptions, floods, and landslides amongst others. The location of Kyushu towards the south-western end of the island chain exacerbates rainfall-related hazards; the island comes under the influence of different continental and tropical/subtropical airmasses and the Asian monsoon resulting in large amounts of rainfall during the Baiu season (Uvo et al., 2001). After the Baiu season, a large number of typhoons makes landfall at Kyushu (Goh and Chan, 2012; Grossman et al., 2014). Owing to the south-north direction alignment of the Kyushu mountains across the centre of the island, the eastern (windward) part of Kyushu is more heavily affected by rainfall. Intense rainfall can in itself be a primary hazard causing flooding, but it can also trigger secondary hazards such as landslides (Kato, 2005; Unuma and Takemi, 2016) and volcanic mudflows/lahars (Miyabuchi et al., 2004). Finally, rainfall has been implicated for initiating volcanic eruptions for certain types of volcanoes such as Mount Unzen (Yamasato et al., 1998), a phenomenon also seen in a number of volcanoes outside of Japan such as Mount St. Helens, USA (Mastin, 1994), and Soufrière Hills, Montserrat (Matthews et al., 2002; Carn et al., 2004; Barclay et al., 2006).

The seasonal variation of wind, rainfall, and stability also have an immediate impact on the dispersal of the volcanic emissions from the volcanoes on the island, as they are the primary deciding factors in the transport, deposition, and remobilisation of volcanic ash (Bonadonna et al., 2012; Wilson et al., 2012). Many of the island's 
volcanoes erupt frequently, while in the case of the Sakurajima volcano ash and volcanic gasses are released almost continuously by eruptions or as passive emissions (Iguchi, 2016). Long-term exposure to these volcanic emissions is known to impact the surrounding communities (Hillman et al., 2012). Studying the climatology of the island can thus help gain a deeper understanding of the seasonality of these emissions and help in the long-term hazard management.

Despite the fact that both the Baiu and the typhoon season receive a large amount of attention, research has tended to focus on specific phenomena (for example Yoshizaki et al., 2000; Uvo et al., 2001; Kato, 2005; Nishiyama et al., 2007; Takemi, 2007a,b; Goh and Chan, 2012; Grossman et al., 2014; Iwasaki, 2014; Takemi, 2014; Unuma and Takemi, 2016). A previous climatological study by Chuda and Niino (2005) focused on the seasonal evolution of stability parameters and precipitable water content in different parts of Japan. The study concluded that on average $\mathrm{PW}_{\mathbf{\Lambda}}$ exhibits a smooth, monotonic behaviour, while high value of $\mathrm{CAPE}_{\mathbf{\Lambda}}$ are mainly constrained between July and September. It was also noted that higher values of CAPE are observed in the south than the north; however detailed analysis over specific parts of Japan was deemed necessary in order to understand the effect of large-scale systems on the parameters. The study did not cover the vertical structure of the atmosphere in detail: this is the aim of this paper and to our knowledge, the first of this kind in the area. It is our hope that these characteristic profiles will be used as benchmarks for climatological and modelling studies of the area, similar to work carried out for midlatitude convective storms over the continental US (Bluestein and Jain, 1985) and the rainy season in the Caribbean (Dunion, 2011), 
and as the atmospheric context for further research on natural hazards focusing on the Baiu, typhoons, volcanic activity, or landslides.

Due to the focus of this work on the broad seasonal behaviours and categorisations of the climate, local circulation, and resulting weather, the finer details of each sounding category will have to be ignored for the time being; the results presented here concern the average response to specific mesoscale conditions. In reality due to the position and the complexity of the topography a large number of well-known but finer-scale phenomena occur, for example heavy convective rainfall over weaker non-convective rainfall (Akiyama, 1978; Houze Jr, 1997) and the Koshikijima and Nagasaki rainbands (Ninomiya and Yamazaki, 1979; Kato, 2005). Although these are not studied in detail they offer a possible future extension using the main framework presented here.

The paper is organised as follows. Section 2 contains a short description of the observational data and the numerical modelling carried out. The categorisation criteria and resulting trajectories per category are presented in Section 3. Different sounding types (both seasonal and per sounding category) and the corresponding rainfall patterns are presented and discussed in Sections 4 and 5 respectively. The main conclusions of the study are summarised in Section 6 . 


\section{Data and Methodology}

\section{$2.1 \quad$ Observations}

The study period is from the 1st of January 1998 to the 31st of December 2013. Kyushu is covered by more than 160 meteorological stations maintained by the Japan Meteorological Agency (JMA), creating a relatively high-resolution observation network, approximately $17 \mathrm{~km}$ spatial resolution (Fig. 1). Rawinsonde stations are located at Kagoshima [southern Kyushu; World Meteorological Organisation (WMO) code: $\left.47827,31.55^{\circ} \mathrm{N} / 130.55^{\circ} \mathrm{E}\right]$ and Fukuoka (Northern Kyushu; WMO code: $47807,33.58^{\circ} \mathrm{N} / 130.38^{\circ} \mathrm{E}$ ), with rawinsondes launched twice daily (at 0000 and 1200 UTC). Sounding data can be accessed from the University of Wyoming archive website (weather.uwyo.edu/upperair/sounding.html). Rainfall data are measured in 10-min intervals by the Japanese nation-wide meteorological network (Automated Meteorological Data Acquisition System; AMeDAS). Archived data are freely available in various formats (hourly, daily, monthly averages and daily maximums of 10-min and 1-h rainfall intensity) and can be accessed from the JMA website (www.data.jma.go.jp/gmd/risk/obsdl/). Here we use the daily average [referred to as daily rainfall $\left(R_{d}\right)$ in the remainder of the paper] and daily 10-min rainfall intensity maximum (peak rainfall intensity; $R_{10}$ ).

Soundings that did not contain non-humidity-based parameter data at all radiosonde observation mandatory levels $(1000,925,850,700,500,400,300,250$, $200,150,100$, and $50 \mathrm{hPa}$ ) or humidity-based parameter data up to $400 \mathrm{hPa}$ were rejected. As in Dunion (2011), in addition to data presented at radiosonde ob- 
servation mandatory levels, a linearly interpolated value is also shown at $600 \mathrm{hPa}$ due to the relatively large gap between the 700 and $500 \mathrm{hPa}$ levels (approximately $2700 \mathrm{~m}$ difference in height). Using other interpolation methods (cubic or spline) showed little difference in the results. Estimates for water vapour mixing ratio above $400 \mathrm{hPa}$ are provided using the European Centre for Medium-Range Weather Forecasts (ECMWF) Re-Analysis data set (ERA-Interim; Dee et al., 2011). The ERAInterim mixing ratio values were adjusted above $400 \mathrm{hPa}$ to avoid discontinuity in the data. Other humidity-based parameters were calculated using the ERA-Interim mixing ratio data. Statistical analysis for wind speed data was carried out using the vector wind speed (value presented in the sounding data), while for wind direction, the wind vector was analysed in $U$ and $V$ components and the final wind direction statistics where calculated as the results of the analysis of the individual components.

Although there are 169 rainfall stations covering Kyushu and the surrounding islands, a number of them have intermittent data. Data from stations covering less than $90 \%$ of the study period can compromise the statistical analysis results (Lau and Sheu, 1988), and thus, the stations were split into two categories, "safe" (120 stations) and "compromised" (49). Among the "safe" stations stations, average data availability is $99.9 \%$ of the study period, with a minimum of $98 \%$. Similar results were noted by Uvo et al. (2001). Amongst the "compromised" stations, results vary with stations providing coverage for as little as $1 \%$ and as much as $88 \%$ of the study period. When results from all stations are shown there will be a clear distinction between the stations categories. In our study statistical analysis is 
carried out using the "safe" stations, but inclusion of all stations did not affect the results drastically. Sounding data were converted from UTC to Japanese Standard Time (JST; JST=UTC+9). All references to dates made here use JST. Results presented were tested for statistical significance using a two-tailed Student's $t$ test at a 95-99.9 confidence level. The statistical checks carried out are described in detail in each section.

\subsection{The HYSPLIT model}

The Hybrid Single-Particle Lagrangian Integrated Trajectory (HYSPLIT; Draxler and Rolph, 2003) model was used to gain insight into the origin of the different air masses that approach Kyushu. The HYSPLIT model uses a moving frame of reference for the advection and diffusion calculations, and a fixed three-dimensional grid as a frame of reference for chemical species concentration calculations. Only the former was utilised here.

The model was used to calculate 5-day backwards trajectories at each sounding time for one year at one sounding station (2009, Kagoshima station). Trajectories were modelled at two heights: 1 and $5 \mathrm{~km}$. The National Centers for Environmental Prediction (NCEP)/National Center for Atmospheric Research (NCAR) reanalysis dataset was used for all calculations (Kalnay et al., 1996). Note that the trajectory modelling was used to complement the sounding and rainfall data and the role it has in the study is mainly informative. 


\section{Sounding and air mass characterisation}

\subsection{Sounding category specification}

When categorising different atmospheric states, it is common to use stability parameters [such as eonvective available potential energy (CAPE), or the K or Lifted Index] and water content parameters [such as precipitable water (PW) content], as their combination is a deciding factor for the type and amount of rainfall on a given day (McCaul and Weisman, 2001; McCaul and Cohen, 2002; McCaul et al., 2005; Takemi, 2007a,b, 2014). The categorisation presented here is based on CAPE and PW for each sounding. The category names were based on the origin and path of the air masses at different heights (continental, oceanic, and mixed; Figs. 2a-c). The specific limits specified below for the present study are based on a compromise between reference values (for example Nishiyama et al., 2007), and the resulting trajectories and sounding characteristics (presented in Section 3.2). A different combination of criteria (PW and the wind field at $850 \mathrm{hPa}$ ) has also been used for the prediction of heavy rainfall during the rainy season in Japan (Nishiyama et al., 2007). Chuda and Niino (2005) showed that CAPE decreases strongly with latitude (on average Fukuoka has half the CAPE compared to Kagoshima). Thus a relatively small value for the CAPE limit is used here to distinguish between days when convection is possible and days that convection is highly unlikely. Note that due to the large number of trajectory data, results shown in Figs. 2a-c are a subset for the sake of figure clarity. Trajectory density calculations are based on the entire dataset. 


\subsubsection{Continental (CNT): Dry; $\mathrm{PW}<30 \mathrm{~mm}$, any CAPE}

Dry soundings were generally associated with both upper and lower air masses originating from the west, over continental Asia. These sounding are characterised as "continental" (CNT; Fig. 2a). Averaged trajectories show little variability in the air masses paths (Figs. 2d,g): The upper air mass indicates an almost completely westerly wind, while for the lower air masses, the most common path passes from South Korea and the Sea of Japan. Results here agree with previous trajectory modelling carried out for Kyushu over the winter season (Kazaoka and Kida, 2006).

\subsubsection{Oceanic (OCN): Moist and Unstable; $\mathrm{PW}>30 \mathrm{~mm}, \mathrm{CAPE}>100 \mathrm{~J} \mathrm{~kg}^{-1}$}

Moist and unstable soundings were mainly associated with both air masses originating over the ocean, leading to the characterisation as "oceanic" (OCN; Fig. 2c). In this case upper air masses mainly originate from the Indian Ocean, while the lower air masses originated from either the Indian or the Pacific Oceans. Some typhoon circulations can also be seen in the data, with air masses from both heights circling east of the station. On average, upper air masses come from a south-westerly point, with the most common path being over the southern coastline of China (Figs. 2f). Results for air masses close to the surface are more variable, and the most common approaches to the station are either from south or the east (Figs. 2i).

\subsubsection{Mixed (MXD): Moist and Stable; $\mathrm{PW}>30 \mathrm{~mm}, \mathrm{CAPE}<100 \mathrm{~J} \mathrm{~kg}^{-1}$}

Moist and stable soundings were generally seen to belong to an "intermediate" case and were characterised as "mixed" (MXD; Fig. 2b). In this case, upper air masses 
approach the station directly from continental Asia passing over the Sea of Japan (westerly winds with a small south-westerly component; Fig. 2e), while the lower air masses either originate from the ocean (south or east of Kyushu) or originate from the continent but pass over central Japan and turn easterly afterwards, becoming moist as they pass over the Pacific (Fig. 2h).

\subsubsection{Categorisation criteria limits}

An effort was made to specify limits that allowed for a categorisation based both on the limit of the parameter chosen, as well as the origin or path of the air masses associated [i.e. analysis of the data has shown that dry (moist/unstable and moist/stable) soundings are generally associated with air masses of continental (oceanic and mixed) origin]. Even if the strict definition of each category is based on the thermodynamic structure and water content of the soundings, in the paper we will be referring to the categories as CNT, OCN, and MXD for ease of language and because, even if it is not the primary characteristic used to define the categories, the naming fits the data as seen from the analysis.

The categorisation criteria are intentionally simple to allow for a broad and manageable categorisation of the trajectories and soundings, leading to statistically significant results. Even though results here are presented for CAPE and PW limits of $100 \mathrm{~J} \mathrm{~kg}^{-1}$ and $30 \mathrm{~mm}$ respectively, the qualitative results of the study hold for CAPE limits between $50-200 \mathrm{~J} \mathrm{~kg}^{-1}$ and PW limits between $25-40 \mathrm{~mm}$. A change in the CAPE limit only affects the number of MXD and OCN soundings (an increased CAPE limit leads to higher number of MXD soundings), while a change in the PW limit affects the number of CNT and MXD/OCN soundings (an increased 
PW limit increases the number of CNT soundings, but does not affect the relative ratio of MXD and OCN soundings). Naturally, the simplicity of the categorisation criteria leads to some generalisations and overlap: atypical trajectories can be seen mixed in each category (for example air masses from the continent included in the OCN soundings). These could be connected with atypical large-scale weather systems dictating the vertical structure of the soundings. The inclusion of these soundings does not affect the average soundings to a significant degree; however, this categorisation should be seen as a first step and each category can easily be further expanded and studied in more detail.

\subsubsection{Seasonal distribution}

The different sounding categories follow the seasonality of PW and CAPE (Fig. 3). Averaged over all available stations, there is a notable difference between the peak of monthly rainfall, which occurs in June due to the rainy season, and average PW and CAPE, which occur in August due to the typhoon season (Fig. 3a). A secondary rainfall peak in September is due to the influence of the westerly jet stream (Aizen et al., 2001). The seasonality of CAPE and PW is consistent with previous results as noted by Chuda and Niino (2005), and the overall behaviour can be explained in terms of the large-scale weather systems as discussed in detail in Section 1. Note that even though on average both PW and CAPE reach a maximum value in August, the seasonal variation of PW follows a smoother profile, with values over $50 \%$ of the maximum for six months. In contrast, CAPE follows a narrow profile, with the increased CAPE period limited to 3 months. This relative "lag" between PW and CAPE is used here to distinguish between the MXD and OCN categories (Fig. 3b). 
The CNT soundings dominate much of the winter season, however they can still occur during spring and autumn with a lower frequency. The MXD soundings can be associated with peaks of monthly rainfall and occur from spring to autumn. The OCN sounding frequency follow a very similar pattern to the typhoon season (Goh and Chan, 2012), mainly occurring during the summer with a peak in August. However that does not mean that typhoons are only related to OCN soundings. The MXD soundings can also be represent days with stratiform rainfall away from the convective centre (Uvo et al., 2001; Wang et al., 2009). As noted from the trajectory analysis, despite some variability, results can be seen as representatives of the early (MXD) and later (OCN) phases of the Asian Monsoon season and the typhoon season (Nishiyama et al., 2007).

The results for the categorisation are relatively similar for both sounding stations (Table 1). The CNT category is the most common, covering $60 \%$ of the total dataset, and also exhibits the largest difference between the two stations - Fukuoka (northern of Kyushu) has 7\% more CNT soundings. The MXD category is the second most common ( $22 \%$ of the total set) and also the least variable. Finally, the OCN category is the least common and is $5 \%$ more likely in Kagoshima (southern Kyushu). This decrease of the OCN soundings is to be expected due to the decrease of CAPE in higher latitudes (Chuda and Niino, 2005). For both sets approximately $2 \%$ where unclassifiable as they lacked data or a PW value.

The "concurrent" set (final row in Table 1), is used in Section 5. It represents days when the entire island is categorised by the same sounding type for a day. Hence, it features a subset of soundings satisfying the following conditions: (i) Same 
resulting category for both 09 and 21 JST soundings, (ii) Same resulting category for both Kagoshima and Fukuoka. This is used to ensure that rainfall results can be linked to a specific atmospheric profile over the whole island. This means that only $30 \%$ of the days are used but it still allows the use of a statistically significant dataset (3508 days).

\subsection{Sounding category characteristics}

Overall averages of wind direction, wind speed and mixing ratio for the "total" dataset (all data from both Kagoshima and Fukuoka) reveal complex distributions at specific heights (Figs. 4a-c). This is to be expected when analysing the dataset as a whole; however, the complexity persists even if analysed seasonally (not shown here). The distribution for wind direction is fairly narrow above $800 \mathrm{hPa}$ (approximately $2 \mathrm{~km}$ ), with an average at $270^{\circ}$, however, in the lower atmosphere it spreads over the whole range, with increased frequencies at $0-80^{\circ}, 100-180^{\circ}$, and $270-360^{\circ}$. The mean profile largely follows the later. Wind speed is narrow at the surface and becomes wider above a height of $400 \mathrm{hPa}(\sim 7.5 \mathrm{~km})$, roughly indicated by the mean and standard distribution values. This is tied with the seasonal variability of the subtropical jet stream (Zhang et al., 2006). A similar pattern can be seen for water vapour mixing ratio: the distribution is wide up to approximately $800 \mathrm{hPa}$ and becomes progressively narrower with height.

Profiles calculated for the three categories using the "total" dataset largely disentangle these distributions (Figs. 4d-f). Specifically, the three profiles follow the trimodal distributions shown for the wind direction and wind speed very closely. In 
the case of the wind direction, the results agree with the trajectory analysis presented in Section 3.1. At low altitudes, CNT is northwesterly, MXD is easterly to southeasterly, and OCN is southerly. Above $800 \mathrm{hPa}$ all profiles have a strong westerly component, however OCN shows a small shift towards southerly, as seen previously. Upper level wind speed reveals the inherent seasonality of the profiles, as it closely follows the seasonal behaviour of the subtropical jet stream (Zhang et al., 2006). Below $600 \mathrm{hPa}$ all profiles converge into a single mean value, showing that the variability in low-level wind is not isolated to a single category. The water vapour mixing ratio profiles are the least clearly defined: the CNT profile are visibly differentiated from the MXD and OCN ones, however the MXD and OCN profiles are relatively similar on average, especially above $600 \mathrm{hPa}$. The CNT profile closely follows the peak in the distribution while the MXD and OCN ones are closer to the upper limits. The data for the profiles are presented in Table 2 as a reference. The wind shear between the near-surface and mid-tropospheric values is summed up in Table 3 which shows the surface values and the $850-500 \mathrm{hPa}$ layer means for different sounding parameters.

The characteristics of the three profiles as discussed previously are also confirmed by the profiles of several sounding parameters (Fig. 5). The CNT and OCN categories represent the upper and lower limits for all parameters: the average surface air temperature is approximately 10 and $27^{\circ} \mathrm{C}$ respectively and the freezing level increases from $750 \mathrm{hPa}$ for $\mathrm{CNT}$ to $580 \mathrm{hPa}$ for OCN (Fig. 5a). The equivalent potential temperature profiles reveal the inherent stability in the CNT profile, while show strong instability for OCN (Fig. 5b). In most cases the MXD profile falls in 
the middle of these two extremes, closer to the OCN category. Despite the relatively large water vapour mixing ratio difference between the MXD and OCN profiles at the lower levels, relative humidity $(\mathrm{RH})$ values are very similar (Fig. 5c). This is due to the difference in the thermal structure of the profiles - the warmer OCN air can hold larger amounts of water vapour, leading to similar $\mathrm{RH}$ values.

For each parameter two statistical tests were carried out, comparing each category with the others as a whole, per year and per level. All parameters passed the first two checks; when using all levels the three different categories are statistically different at a 95-99.9 confidence level. When using specific levels some tests failed: wind speed at very high levels (150 and $100 \mathrm{hPa}$ ) between all categories, and mixing ratio at 300 and $400 \mathrm{hPa}$ between the MXD and OCN categories. For the majority of the levels all categories were found to be statistically different from each other however it is safer to compare the sounding as a whole in order to categorise it.

\section{Seasonal and annual variation of the sounding}

\section{categories}

The frequency of the three profiles has a strong seasonal trend: CNT mainly occurs from late autumn until early spring, MXD is at its peak frequency in late spring and early autumn, and OCN is mainly associated with the summer season. This can be seen in the seasonal characteristics of some specific parameters as well (water vapour content, wind direction, and upper tropospheric wind speed). Here we will examine this in more detail by comparing the average profile for each category and 
the same profile based on season-specific data (Fig. 6).

Most profiles exhibit only a small amount of variability even outside of their "representative" seasons. The sounding category with the least variability is the OCN (Figs. 6g-i). This is to be expected as it only occurs within a narrow time frame and the mean OCN profile is close to the summer profile. The largest difference can be seen for wind direction, where especially close to the surface there is a $90^{\circ}$ shift to easterly between summer and autumn. The CNT and MXD soundings exhibit similar amounts of variability. Overall, the most variable characteristic is the wind speed owing to the strong seasonal variability of the subtropical jet stream (Zhang et al., 2006). Other than that, the MXD soundings are noticeably different in autumn in the case of wind direction $\left(45-90^{\circ}\right.$ more northerly than the average profile) and in spring in the case of $\mathrm{RH}$ (10-20\% more humid that the average profile).

The three categories display different amounts of annual variability (Fig. 7). On average the CNT profiles are the least inter-annually variable: the difference from the mean value is within $24.5^{\circ}, 8.5 \mathrm{~m} \mathrm{~s}^{-1}$, and $9.4 \%$ for wind direction, wind speed, and RH respectively. The MXD soundings exhibit the largest amount of variability in wind direction close to the surface, with a range of over $100^{\circ}$, is reduced to $28.6^{\circ}$ above $800 \mathrm{hPa}$. Wind speed varies significantly above $400 \mathrm{hPa}$ with a maximum range of $13.8^{\circ}$ at $200 \mathrm{hPa}$, while $\mathrm{RH}$ has similar range to $\mathrm{CNT}$. The OCN soundings show the largest variability in wind direction (relatively constant range of approximately $\left.73^{\circ}\right)$ and $\mathrm{RH}(9.4 \%$ close to the surface increasing up to $33 \%$ above $600 \mathrm{hPa})$, however has a relatively small range for wind speed $\left(6.2 \mathrm{~m} \mathrm{~s}^{-1}\right)$. 
Although not shown here, the temperature profiles exhibit some seasonal variation as expected (lower temperatures in winter and higher temperatures in the summer season) with average surface temperatures for CNT ranging between $7-13^{\circ} \mathrm{C}$, MXD between $16-24^{\circ} \mathrm{C}$, and $\mathrm{OCN} 18-26^{\circ} \mathrm{C}$, however show little annual variation (between $1-3^{\circ} \mathrm{C}$ ). The statistical significance of the seasonal and annual variation from the average for each parameter was checked for each category. All variation was found to be statistically insignificant at a 95-99.9 confidence level.

\section{Seasonal variation of rainfall}

Here we will study the rainfall patterns in Kyushu depending on season as well as conditions related to the sounding categories established earlier. For the categoryspecific rainfall, only a subset of the rainfall data are used: days when both rawinsonde stations are characterised by the same sounding category for both the 0900 and 2100 JST soundings, in order to establish a strong link between the rainfall and vertical profile, and allow the study of a "quasi-steady-state" rainfall response.

This is referred to as the "concurrent" set. Due to this selection tends to exclude "transitional" rainfall episodes. For example during the Baiu season some times accumulated high values of CAPE are found in the south and neutral conditions on the north after the CAPE has been released due to rainfall, leading to a mix of convective and non-convective rainfall respectively (Akiyama, 1978). Although this plays an important role in the long-term climatological behaviour of the rainfall, a detailed analysis is outside the general scope of this study, but will be considered in future work. 
Daily rainfall distribution shows strong seasonal variability (Fig. 8). During winter, with the exception of the Yakushima island in the south of Kyushu, rainfall is limited to an average of $0-2.5 \mathrm{~mm}$ day $^{-1}$ in the north and up to $5 \mathrm{~mm} \mathrm{day}^{-1}$ in the south. This is due to the different paths the air masses follow: in the north, air passes through the Korea and Tsushima Straits obtaining a smaller amount of moisture, while in the south air masses follow a more favourable path for the moisture transport over the East China Sea (Uvo et al., 2001). The northern part of the Yakushima island $\left(30.35^{\circ} \mathrm{N}, 130.53^{\circ} \mathrm{E}\right)$ receives more than double the average precipitation (7.5-10 $\mathrm{mm} \mathrm{day}^{-1}$ ) compared to both the rest of stations in Kyushu and the nearby islands, as well as the southern part of the same island. Rainfall during spring and autumn are relatively similar, with average daily rainfall ranging between 5-10 $\mathrm{mm} \mathrm{day}^{-1}$ at southern and south-eastern part of the island; however, during autumn there is a shift towards a more eastern distribution due to the passage of typhoons (Uvo et al., 2001). During the summer season, the island receives the most precipitation with average daily rainfall values more than $10 \mathrm{~mm}$ day $^{-1}$. Heavy rainfall is concentrated on the central, southern, and eastern parts of the island $\left(R_{d}>10 \mathrm{~mm} \mathrm{day}^{-1}\right)$, while rainfall peaks are mainly concentrated in the central part of the island.

Different rainfall patterns are now examined for each sounding category (Fig. 9). Barring some differences in magnitude, rainfall pattern per sounding category show similarities with rainfall patterns per season, specifically CNT with winter, MXD with spring and autumn, and OCN with summer. The differences in magnitude can be expected as different seasons can be characterised by a combination 
of sounding categories (for example spring has an almost equal number of CNT and MXD soundings). The CNT profile closely match the winter rainfall pattern in both distribution and magnitude, as most of the winter season is comprised of CNT-type soundings. The MXD category rainfall distributions resemble the spring and autumn distribution, with rainfall focused mainly over the southern and southwestern part of the island, however the daily rainfall values are different, affected by the CNT-type days.

The MXD profile features the largest daily rainfall values: the southern part of the island sees rainfall over $18 \mathrm{~mm} \mathrm{day}^{-1}$, while stations along the eastern coast record rainfall over $24 \mathrm{~mm}$ day $^{-1}$. Considering that this profile is specifically chosen to have less than $100 \mathrm{~J} \mathrm{~kg}^{-1}$ of CAPE, and this continues for the whole day, two assumptions can be made: either it is non-convective, frontal rainfall, or typhoonrelated rainfall as a large amount of water vapour is pushed towards the island in a western-northwestern flow (Uvo et al., 2001; Wang et al., 2009).

For the OCN category, rainfall is mainly concentrated in the middle of the island, pointing towards strong orographic triggering of rainfall (Houze, 2012). This is to be expected, as the OCN profiles, satisfy the conditions prescribed by Lin et al. (2001) for heavy orographic precipitation. The distribution of rainfall has similarities with that presented by Unuma and Takemi (2016), for the distribution of quasistationary convective systems. The OCN distribution partially resembles the rainfall distribution over the summer season in Fig. 8. When looking at the season as a whole, rainfall patterns are the results of both the OCN and the MXD categories. All categories include some days with atypical rainfall patterns $\overline{\overline{\mathbf{\lambda}}}_{\mathbf{2}}$ however overall 
the OCN category has the most variable rainfall response. For example these are days when the CAPE-release mechanism from south to north described previously (Akiyama, 1978) has not led to a decrease of CAPE below $100 \mathrm{~J} \mathrm{~kg}^{-1}$. On these days the rainfall response looks similar to a MXD day with a gradual decrease of daily rainfall towards the north. Aside from that, there are also days with orographic rainfall over some parts (south or north), days with the Nagasaki or Koshikijima lines, as well as days with strong rainfall over the whole island. However these atypical responses get averaged out in the final pattern and the average response is an orographic rainfall regime.

The statistical significance of the difference in the rainfall response for each category was checked for: all data, per year, and per station. When using the distributions as a whole or when comparing data per year, all categories were found to have a statistically significantly different response. When comparing data per station, a number of stations failed the test between the MXD and OCN categories (for example stations in the north-west part of the island or ones located on mountains). Similarly to the vertical profiles discussed in Section 3.2, when categorising the rainfall response it is suggested to use as many stations as possible to get a statistically significant result.

The relation between the topography and resulting rainfall is shown in Figure 10, both for daily and peak rainfall. Strong orographic forcing can be seen in the case of the OCN category, where large values of both daily rainfall and rainfall intensity are seen for large station heights. This is partially true for the MXD sounding as well, although the orographic effect is clearly less important. The pattern previously seen 
for the MXD rainfall is reflected in the latitude and longitude scatter plots (Figs. 10b,c and 10e,f): large amounts of rainfall occur to the east $\left(\mathrm{LON}>130^{\circ}\right)$ and the south $\left(\mathrm{LAT}<33^{\circ}\right)$. Specifically in the south-north alignment the increase in rainfall is almost linear. For OCN, large amounts of rainfall are typically limited in the middle of both ranges, following the island topography. Results for the CNT category show that rainfall is generally distributed evenly across the island with some elements of orographically-forced rainfall and an increase towards the south. On average, MXD soundings lead to larger daily rainfall but lower peak rainfall (non-convective rainfall), compared to the OCN soundings (convective rainfall). Results agree with the seasonal analysis presented by Uvo et al. (2001).

Histograms of rainfall reveal a similar distribution between the MXD and OCN categories (Fig. 11). When each individual value from the whole dataset is included, rainfall rate frequency decreases almost exponentially for increased rates. The peak in the rainfall distribution for all three categories is at $0-5 \mathrm{~mm} \mathrm{day}^{-1}$ for daily rainfall and $0-2 \mathrm{~mm}(10 \mathrm{~min})^{-1}$ for the peak rainfall intensity. For daily rainfall, the CNT category shows the largest decrease, and while the MXD and OCN categories are similar, MXD consistently has a higher frequency. Averaged over the 16-year period for each station this leads to similar distributions for the two categories with the same peak averaged daily rainfall. However, in the MXD case the distribution trails more towards the higher values, leading to a larger overall average (Figs. 11a,b and Table 4). The opposite is true for daily peak rainfall intensity, here the OCN category has consistently higher values, leading to different peak frequencies and a higher average peak rainfall intensity (Figs. 11c,d and Table 4). 
Average values of stability criteria allow for a quick summary of each category

(Table 4). The CNT category represents cold, dry air masses from continental Asia do not have enough time to gather moisture east of Kyushu. The result is very strong atmospheric stability reflected in all parameters, with little to no rainfall generated as a result. The MXD category usually involves cold and dry air masses for the west mixing with moist, warmer air masses from the Pacific. This leads to large amounts of non-convective rainfall, with smaller peak rainfall rates but large overall rainfall per day, most likely caused by mid-latitude synoptic cyclones and the Baiu stationary front or by typhoon-forced circulation (Uvo et al., 2001). Finally, the OCN category represents the warm, moist oceanic air masses either from the Indian or the Pacific Ocean. These exhibit low atmospheric stability and rainfall is convective and shows evidence of orographical triggering, leading to shorter duration but higher peak rainfall intensity. Although not shown here, using data from all stations (including statistically "compromised" stations) led to a $0.1-3.5 \%$ change in the final rainfall values.

\section{Summary and conclusions}

Rawinsonde data were used to study the seasonality of the weather in the island of Kyushu in southern Japan over a 16-year study period. In the past a climatological analysis has been carried out across Japan by Chuda and Niino (2005) studying the seasonal variation of several mesoscale parameters including PW and CAPE. Here the vertical structure of the atmosphere was studied and the analysis was focused on distinguishing the different atmospheric sounding categories that are 
tied to the seasonal climatological behaviour. Data from the rawinsondes along with air mass trajectories revealed three distinct categories, based on water content (a PW threshold of $30 \mathrm{~mm}$ ) and stability (a CAPE threshold of $100 \mathrm{~J} \mathrm{~kg}^{-1}$ ) criteria, as well as air mass origins: the dry, stable air masses that originate from continental Asia and occur mainly during winter (CNT), the moist, unstable air masses that originate from the Indian or the Pacific oceans (OCN), and an intermediate, mixed, case when upper air masses from the continent mix with air masses passing over the Pacific (MXD). Vertical profiles based on the three categories were found to be statistically robust and were seen to disentangle the complex distributions of the several atmospheric parameters. The annual variability in the characteristics of the sounding categories calculated here was seen to be sufficiently small, as to allow the long-term use of the study's results.

The rainfall response over Kyushu for each category was also studied using rainfall data from the AMeDAS network of the Japan Meteorological Agency. Based on the particular characteristics of each sounding category, a distinct rainfall response was noted: very low amounts of rainfall in the CNT case, high amounts of non-convective rainfall in the MXD case, and high amounts of convective rainfall in the OCN case. Average daily rainfall rates are similar for the MXD and OCN categories, but peak rainfall rates are higher in the OCN case. Parallels in the rainfall response for each category were also drawn between the seasonal variation of rainfall patterns and the frequency of occurrence for each sounding category: the rainfall patterns over the winter season corresponded to the CNT case, spring and autumn was the combined effect of the CNT and MXD settings, while rainfall over 
the summer corresponded to a combination of the OCN and MXD profiles.

The results from this study represent the first effort to create average atmospheric profiles in this region. It is our hope that they will be used and expanded upon in the future to help enhance our understanding of the climatological variability in the area, as well as help in the study and modelling of atmospheric natural hazards in the Kyushu area as well as the extended region. The study focused mainly on the use of observational data, using modelling only to fill in some gaps in observational data (humidity-based parameters over a height of $400 \mathrm{hPa}$ ), and for trajectory modelling, which was used mainly to gain a general insight on the air masses. Numerical weather prediction model capability of reproducing the results found here will be tested in the future in long, climatological simulations. Finally, the capability of the averaged vertical profiles to reproduce the rainfall patterns discussed here and to replicate known volcanic ash dispersal patterns from the Sakurajima volcano will also be tested in an idealised setting.

\section{Acknowledgements}

Alexandros P. Poulidis was funded by the Japan Society for the Promotion of Sciences (JSPS). The authors would like to thank Ian Renfrew and Takashi Unuma for comments on the manuscript draft and useful discussions and two anonymous reviewers for the helpful comments. All data analysis was carried out using Matlab. 


\section{References}

Ackermann P. 1997. The four seasons. Japanese images of nature: Cultural perspectives : 36 .

Aizen EM, Aizen VB, Melack JM, Nakamura T, Ohta T. 2001. Precipitation and atmospheric circulation patterns at mid-latitudes of Asia. Int. J. Climatol. 21(5): 535-556, doi:10.1002/joc.626.

Akiyama T. 1978. Mesoscale pulsation of convective rain in medium-scale distrubances developed in Baiu front. J. Meteorol. Soc. Japan 56: 448-451.

Barclay J, Johnstone JE, Matthews AJ. 2006. Meteorological monitoring of an active volcano: Implications for eruption prediction. J. Volcanol. Geoth. Res. 150: 339358, doi:10.1016/j.jvolgeores.2005.07.020.

Bluestein HB, Jain MH. 1985. Formation of mesoscale lines of pirecipitation: Severe squall lines in Oklahoma during the spring. J. Atmos. Sci. 42(16): 1711-1732.

Bonadonna C, Folch A, Loughlin S, Puempel H. 2012. Future developments in modelling and monitoring of volcanic ash clouds: outcomes from the first IAVCEIWMO workshop on Ash Dispersal Forecast and Civil Aviation. Bull. Volcanol. 74: 1-10, doi:10.1007/s00445-011-0508-6.

Carn SA, Watts RB, Thompson G, Norton GE. 2004. Anatomy of a lava dome collapse: The 20 march 2000 event at Soufrière Hills Volcano, Montserrat. J. Volcanol. Geoth. Res. 131: 241-264, doi:10.1016/S0377-0273(03)00364-0.

Chuda T, Niino H. 2005. Climatology of environmental parameters for mesoscale 
convections in Japan. J. Meteorol. Soc. Japan 83(3): 391-408, doi: 10.2151/jmsj.83.391.

Dee DP, Uppala SM, Simmons AJ, Berrisford P, Poli P, Kobayashi S, Andrae U, Balmaseda MA, Balsamo G, Bauer P, Bechtold P, Beljaars ACM, van de Berg L, Bidlot J, Bormann N, Delsol C, Dragani R, Fuentes M, Geer AJ, Haimberger L, Healy SB, Hersbach H, Holm EV, Isaksen L, Kallberg P, Kohler M, Matricardi M, Mcnally AP, Monge-Sanz BM, Morcrette JJ, Park BK, Peubey C, de Rosnay P, Tavolato C, Thepaut JN, Vitart F. 2011. The ERA-Interim reanalysis: Configuration and performance of the data assimilation system. Q. J. R. Meteorol. Soc. 137(656): 553-597, doi:10.1002/qj.828.

Draxler RR, Rolph GD. 2003. HYSPLIT (HYbrid Single-Particle Lagrangian Integrated Trajectory) model access via NOAA ARL READY website. NOAA Air Resources Laboratory, Silver Spring. http://www.arl.noaa.gov/ready/hysplit4.html, Accessed: 2016-03-11.

Dunion J. 2011. Rewriting the climatology of the tropical North Atlantic and Caribbean Sea atmosphere. J. Clim. 24(3): 893-908, doi: 10.1175/2010JCLI3496.1.

Goh AZC, Chan JCL. 2012. Variations and prediction of the annual number of tropical cyclones affecting Korea and Japan. Int. J. Climatol. 32(2): 178-189, doi:10.1002/joc.2258.

Gray WM. 1968. Global view of the origin of tropical disturbances and storms. Mon. Weather Rev. 96(10): 669-700. 
Grossman MJ, Zaiki M, Nagata R. 2014. Interannual and interdecadal variations in typhoon tracks around Japan. Int. J. Climatol. 2527: 2514-2527, doi: 10.1002/joc.4156.

Hillman SE, Horwell CJ, Densmore AL, Damby DE, Fubini B, Ishimine Y, Tomatis M. 2012. Sakurajima volcano: a physico-chemical study of the health consequences of long-term exposure to volcanic ash. Bull. Volcanol. 74: 913-930.

Houze RA. 2012. Orographic effects on precipitating clouds. Rev. Geophys. 50, doi: 10.1029/2011RG000365.

Houze Jr RA. 1997. Stratiform precipitation in regions of convection: A meteorological paradox? Bull. Am. Meteor. Soc. 78: 2179-2196, doi:10.1175/15200477(1997)078<2179:SPIROC > 2.0.CO;2.

Iguchi M. 2016. Method for real-time evaluation of discharge rate of volcanic ash - Case study on intermittent eruptions at the Sakurajima volcano, Japan -. J. Disaster Res. 11: 4-14, doi:10.20965/jdr.2016.p0004.

Iwasaki H. 2014. Increasing trends in heavy rain during the warm season in eastern Japan and its relation to moisture variation and topographic convergence. Int. J. Climatol. 2163: 2154-2163, doi:10.1002/joc.4115.

Kalnay E, Kanamitsu M, Kistler R, Collins W, Deaven D, Gandin L, Iredell M, Saha S, White G, Woollen J, Zhu Y, Leetmaa A, Reynolds R, Chelliah M, Ebisuzaki W, Higgins W, Janowiak J, Mo KC, Ropelewsji C, Wang J, Jenne R, Joseph D. 1996. The NCEP/NCAR 40-year reanalysis project. Bull. Am. Meteorol. Soc. 77: $437-471$. 
Kato T. 2005. Statistical study of band-shaped rainfall systems, the Koshikijima and Nagasaki lines, observed around Kyushu island, Japan. J. Meteorol. Soc. Japan 83(6): 943-957, doi:10.2151/jmsj.83.943.

Kazaoka R, Kida H. 2006. Characteristic Transport Route of Air Parcels Arriving over Northern Japan in January. Sola 2: 172-175, doi:10.2151/sola.2006-044.

Lau KM, Sheu PJ. 1988. Annual cycle, quasi-biennial osciallation, and southern oscillation in global precipitation. J. Geophys. Res. 93: 10975-10988, doi: 10.1029/JD093iD09p10975.

Lin YL, Chiao S, Wang TA, Kaplan ML, Weglarz RP. 2001. Some common ingredients for heavy orographic rainfall. Weather Forecast. 16(6): 633-660, doi: 10.1175/1520-0434(2001)016<0633:SCIFHO >2.0.CO;2.

Mastin LG. 1994. Explosive tephra emissions at Mount St. Helens. 1989-1991: The violent escape of magmatic gas following storms? Geol. Soc. Am. Bull. 106: 175185, doi:10.1130/0016-7606(1994)106,0175:ETEAMS.2.3.CO;2.

Matthews AJ, Barclay J, Carn S, Thompson G, Alexander J, Herd R, Williams C. 2002. Rainfall-induced volcanic activity in Montserrat. Geophys. Res. Lett. (13): 1-4, doi:10.1029/2002GL014863.

McCaul EWJ, Cohen C. 2002. The impact on simulated storm structure and intensity of variations in the mixed layer and moist layer depths. Mon. Weather. Rev. 130: $1722-1748$.

McCaul EWJ, Cohen C, Kirkpatrick C. 2005. The sensitivity of simulated storm 
structure, intensity, and precipitation efficiency to environmental temperature. Mon. Weather. Rev. 133: 3015-3037.

McCaul EWJ, Weisman ML. 2001. The sensitivity of simulated supercell structure and intensity to variations in the shapes of environmental buoyancy and shear profiles. Mon. Weather. Rev. 129: 664-687.

Miyabuchi Y, Daimaru H, Komatsu Y. 2004. Landslides and lahars triggered by the rainstorm of June 29, 2001, at Aso Volcano, Southwestern Japan. Chikei 25: $23-43$.

Ninomiya K, Yamazaki K. 1979. Heavy rainfalls associated with frontal depression in Asian subtropical humid region (II) Mesoscale features of preciptation, radar echoes and stratification. J. Meteorol. Soc. Japan 57: 399-412.

Nishiyama K, Endo S, Jinno K, Uvo CB, Olsson J, Berndtsson R. 2007. Identification of typical synoptic patterns causing heavy rainfall in the rainy season in Japan by a Self-Organizing Map. Atmos. Res. 83(2-4 SPEC. ISS.): 185-200, doi:10.1016/j.atmosres.2005.10.015.

Takemi T. 2007a. A sensitivity of squall-line intensity to environmental static stability under various shear and moisture conditions. Atmos. Res. 84(4): 374-389, doi:10.1016/j.atmosres.2006.10.001.

Takemi T. 2007b. Environmental stability control of the intensity of squall lines under low-level shear conditions. J. Geophy. Res. 112: D24110, doi: 10.1029/2007JD008793. 
Takemi T. 2014. Convection and precipitation under various stability and shear conditions: Squall lines in tropical versus midlatitude environment. Atmos. Res. 142: 111-123, doi:10.1016/j.atmosres.2013.07.010.

Unuma T, Takemi T. 2016. Characteristics and environmental conditions of quasistationary convective clusters during the warm season in Japan. Q. J. R. Meteorol. Soc. doi:10.1002/qj.2726.

Uvo CB, Olsson J, Morita O, Jinno K, Kawamura A, Nishiyama K, Koreeda N, Nakashima T. 2001. Statistical atmospheric downscaling for rainfall estimation in Kyushu Island, Japan. Hydrol. Earth Syst. Sci. 5(2): 259-271, doi:10.5194/hess5-259-2001.

Wang B, Ho L. 2002. Rainy season of the asian-pacific summer monsoon. J. Clim. 15: 386-398, doi:10.1175/1520-0442(2002)015<0386:RSOTAP > 2.0.CO;2.

Wang Y, Wang Y, Fudeyasu H. 2009. The role of Typhoon Songda (2004) in producing distantly located heavy rainfall in Japan. Mon. Weather Rev. 137: 3699-3716, doi:10.1175/2009MWR2933.1.

Wilson TM, Stewart C, Sword-Daniels V, Leonard GS, Johnston DM, Cole JW, Wardman J, Wilson G, Barnard ST. 2012. Volcanic ash impacts on critical infrastructure. Physics and Chemistry of the Earth, Parts $A / B / C$ 45: 5-23, doi: 10.1016/j.pce.2011.06.006.

Yamasato J, Kitagawa S, Komiya M. 1998. Effect of rainfall on dacitic lava dome collapse at Unzen volcano, Japan. Pap. Meteorol. Geophys. 48(3): 73-78. 
698

699

700

701

702

Yoshizaki M, Kato T, Tanaka Y, Shoji Y, Seko H, Arao K, Kazuo M. 2000. Analytical and numerical study of the 26 June 1998 orographic rainband observed in western Kyushu, Japan. J. Meteorol. Soc. Japan 78(6): 835-856.

Zhang Y, Kuang X, Guo W, Zhou T. 2006. Seasonal evolution of the uppertropospheric westerly jet core over East Asia. Geophys. Res. Let. 33(11): 3-6. 


\section{$8 \quad$ Figures}
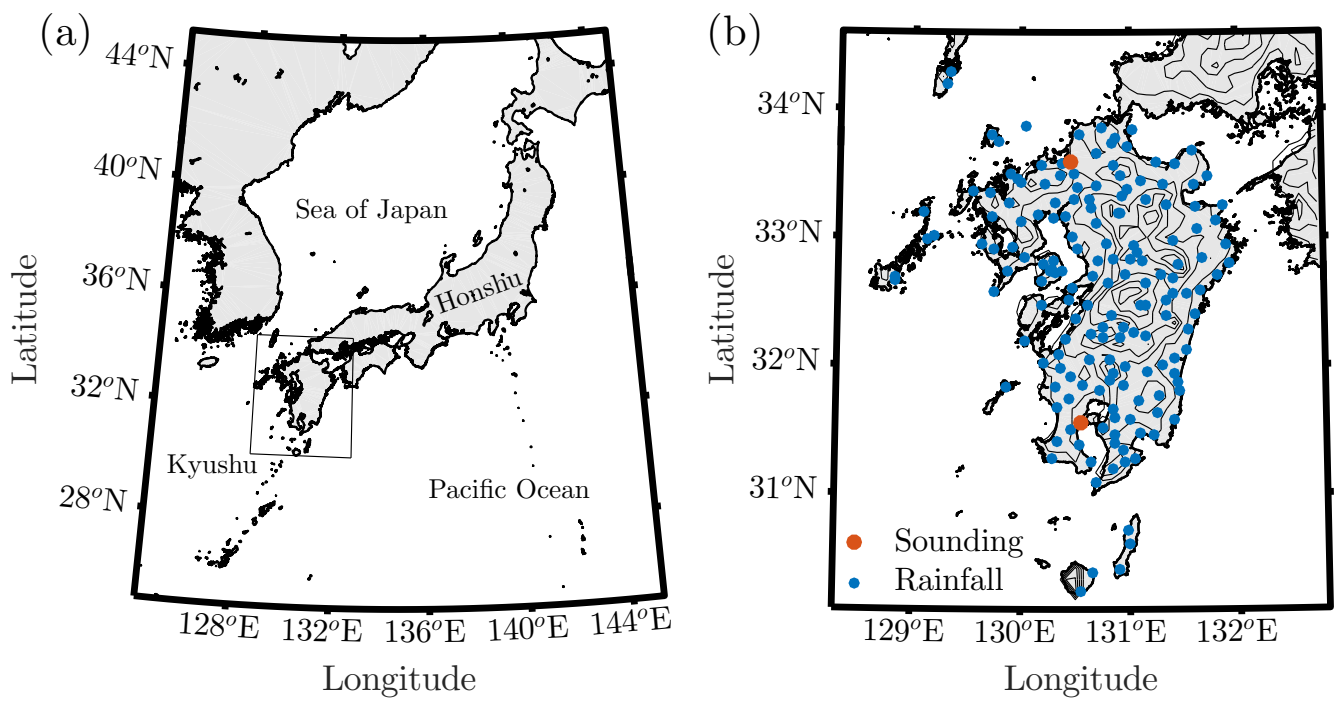

Figure 1: (a) Map of Kyushu and the surrounding area. (b) Locations of "Sounding" stations (red; provide both sounding and rainfall data) and "rainfall" (AMeDAS) stations (blue; only provide rainfall data). Height contours start at $100 \mathrm{~m}$ and every $200 \mathrm{~m}$ after. 
(a)
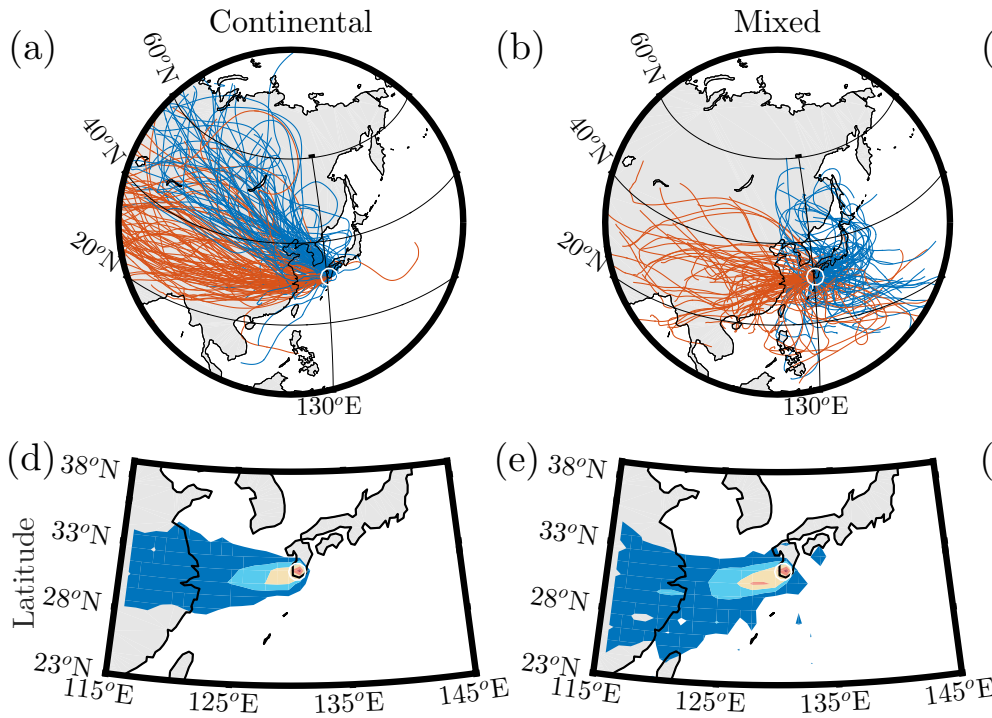

b)
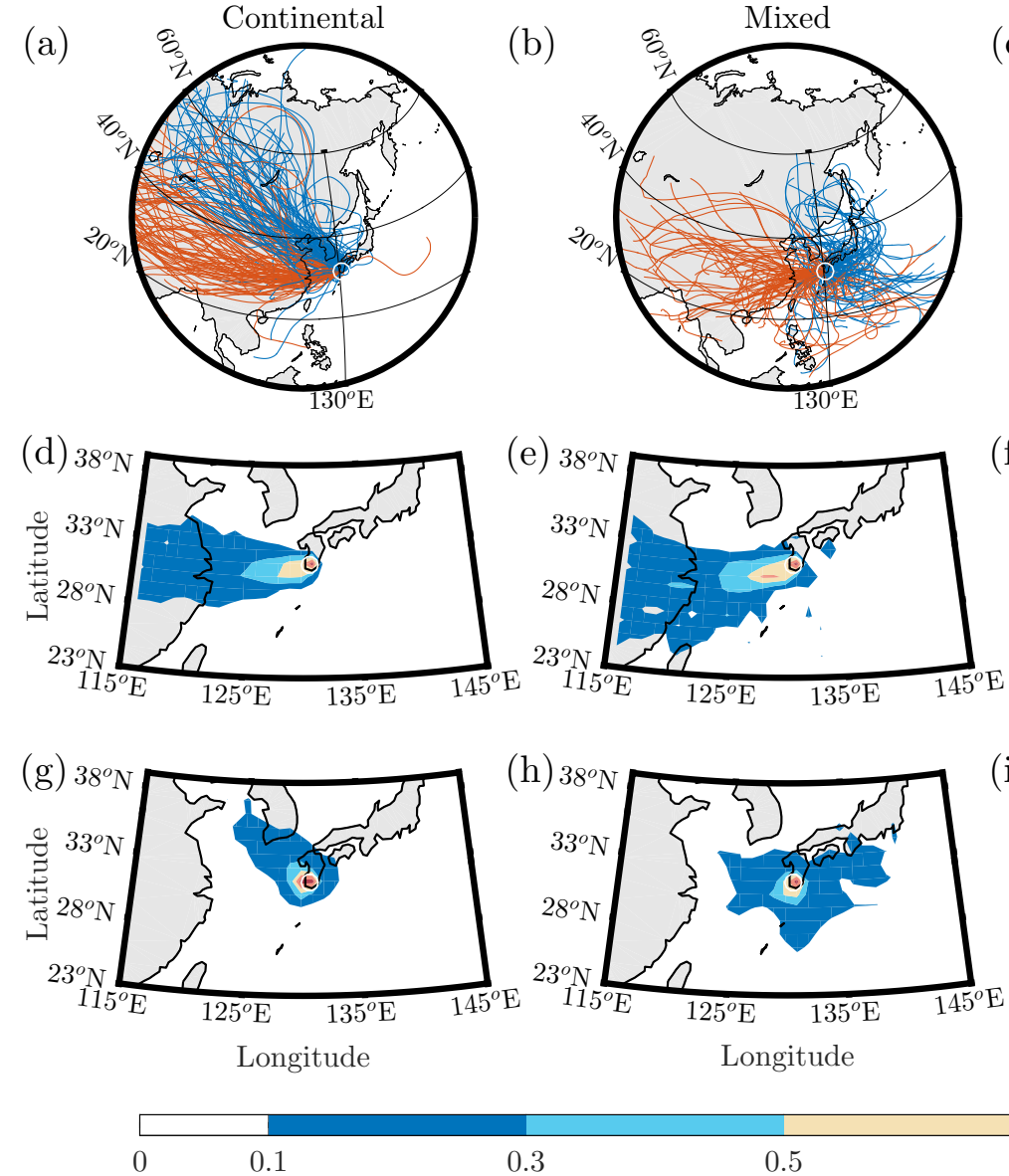

0.3

Normalised Trajectory Density
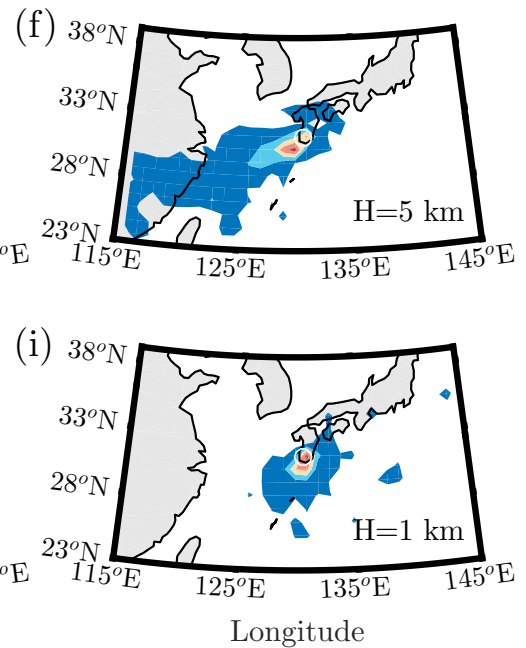

(c)

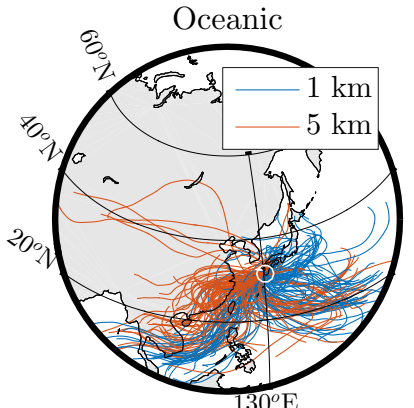

0.9

Figure 2: Subset of the five-day back trajectories for: (a) Continental (CNT), (b) Mixed (MXD), and (c) Oceanic (OCN) air masses for that were identified at 0900 and 2100 JST (0000 and 1200 UTC) throughout 2009. Normalised trajectory density (calculated for all 2009 data) is shown for: (d)-(f) all categories at $5 \mathrm{~km}$, and (g)-(i) all categories at $1 \mathrm{~km}$. The trajectories were calculated using the HYSPLIT model, at 1 and $5 \mathrm{~km}$ (blue and red lines respectively at Panels a-c) originating from the Kagoshima sounding station (white circle). Trajectory density was calculated at a $1^{\circ}$ resolution. 

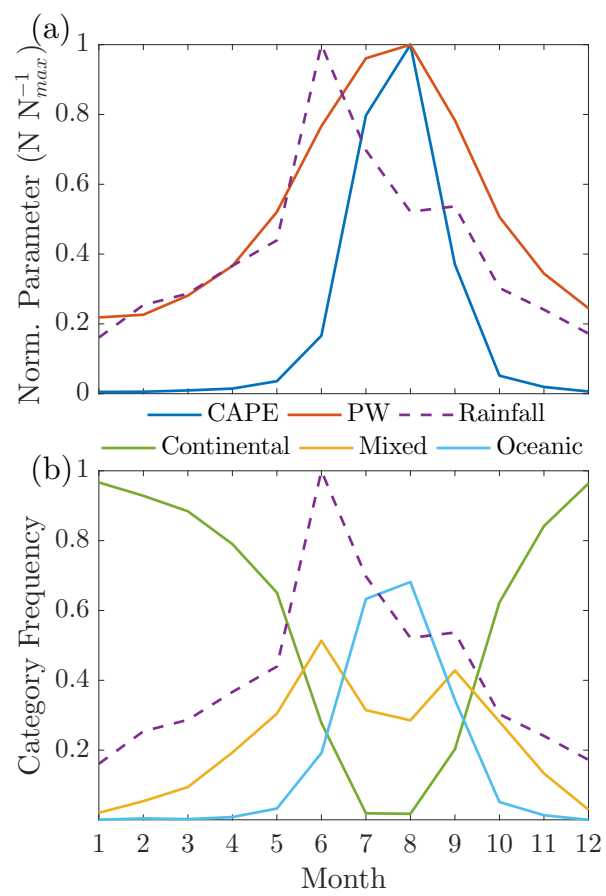

Figure 3: (a) Average normalised values of monthly rainfall intensity, CAPE, and PW for every month from 1998-2013. (b) Frequency of occurrence of each sounding category and normalised rainfall per month. 


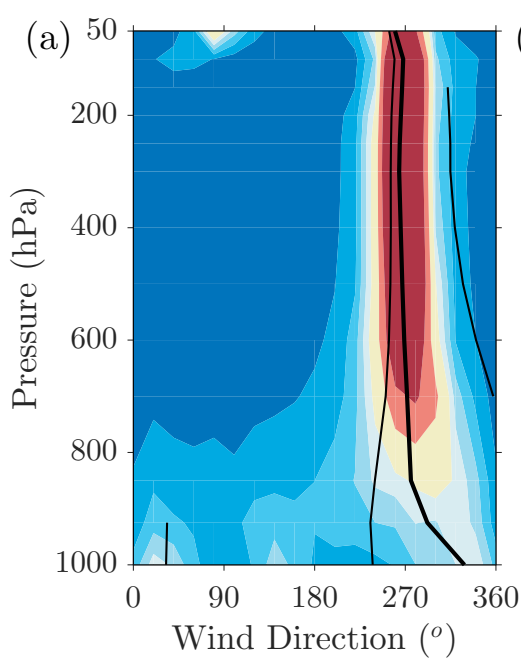

(b)
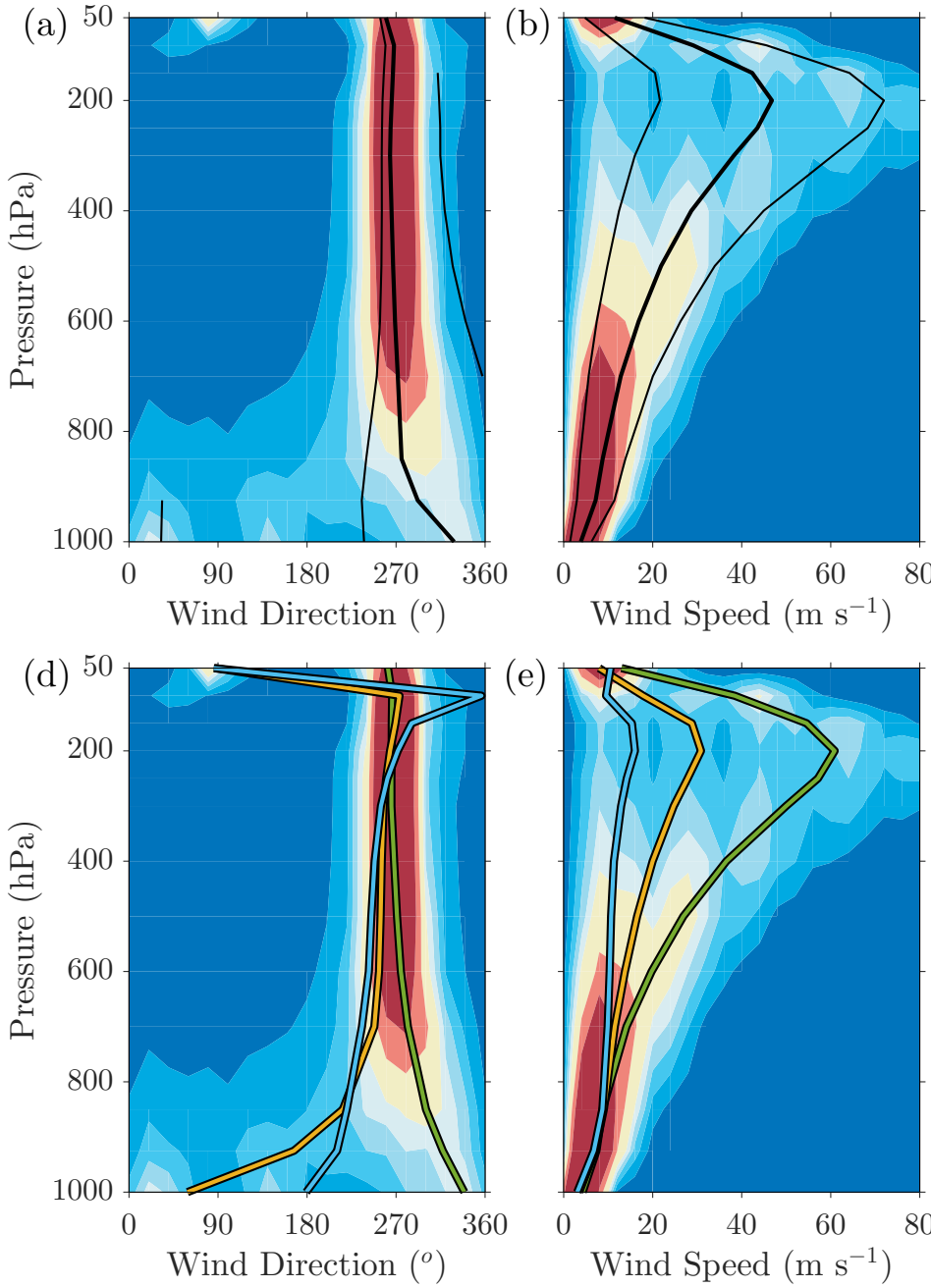

(e)

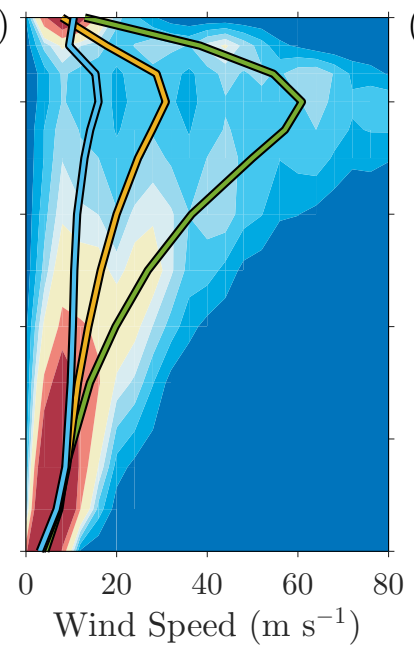

(c)

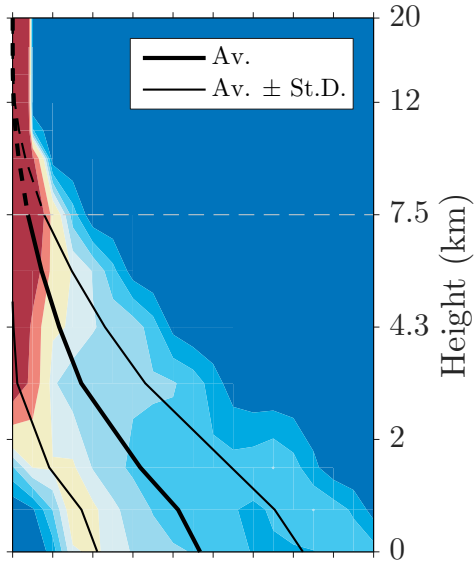

$\begin{array}{lllllllll}0 & 2 & 4 & 6 & 8 & 10121416 & 18\end{array}$ Mixing Ratio $\left(\mathrm{g} \mathrm{kg}^{-1}\right)$

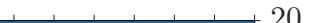

$\begin{array}{lllllllll}0 & 2 & 4 & 6 & 8 & 10 & 121416 & 18\end{array}$ Mixing Ratio $\left(\mathrm{g} \mathrm{kg}^{-1}\right)$

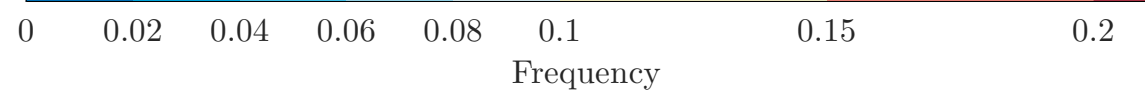

Figure 4: Contoured frequency by altitude diagrams of (a),(d) Wind direction, (b),(e) Wind speed, and (c), (f) Water vapour mixing ratio, overlaid with the combined 16-year average (i.e. all sounding data) and average plus/minus one standard deviation [(a)-(c)], and the 16-year averages for the CNT, MXD, and OCN sounding types [(d)-(f)]. Frequency of occurrence bins where calculated at each level using bin sizes of $20^{\circ}, 5 \mathrm{~m} \mathrm{~s}^{-1}$, and $1 \mathrm{~g} \mathrm{~kg}^{-1}$, respectively. Water vapour mixing ratio data above $400 \mathrm{hPa}$ (dashed) were estimated using ECMWF Era-Interim data. 


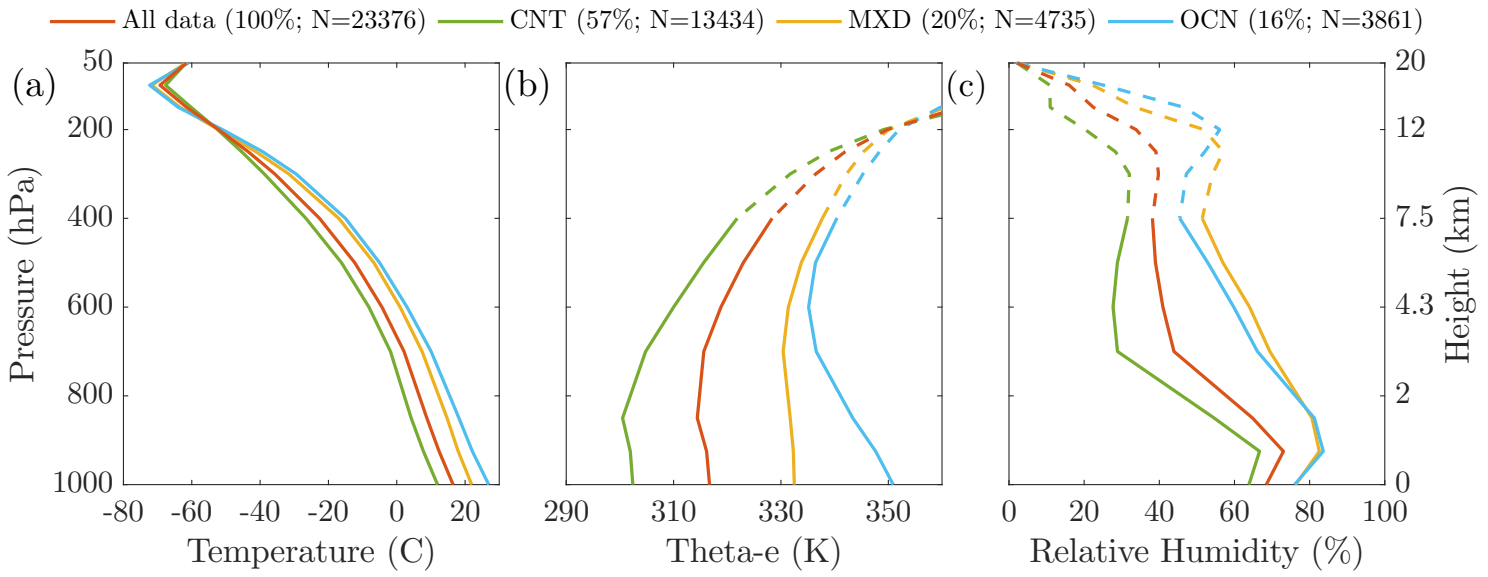

Figure 5: Mean sounding parameters for each sounding category, and the combined average across the study period (1998-2013): (a) Temperature, (b) Equivalent potential temperature, (c) Relative humidity. In the legend, numbers in brackets indicate the percentage and total number of soundings per category. 

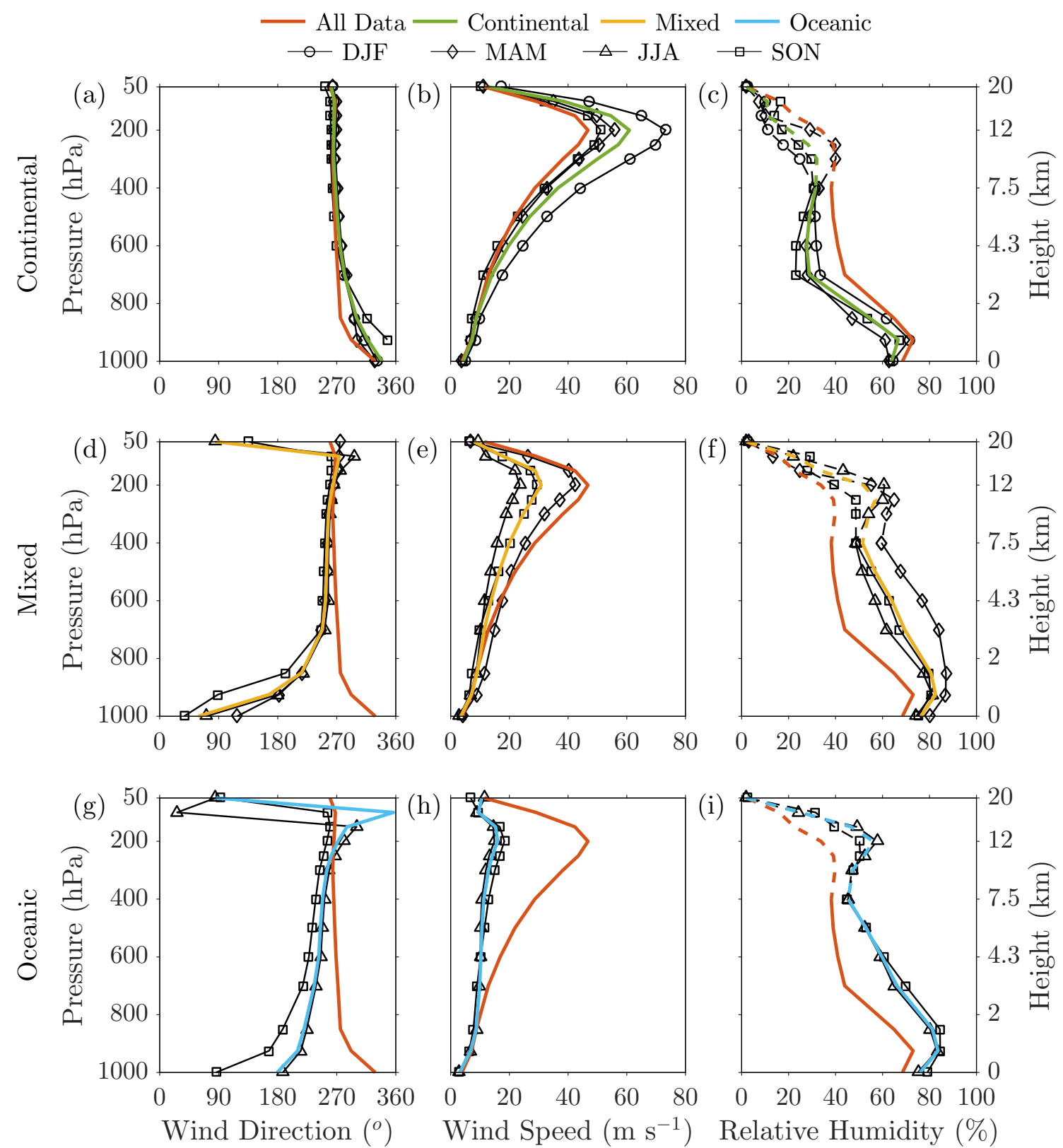

Figure 6: Average wind direction (first column), wind speed (second column), and relative humidity (third column) for: (a)-(c) CNT, (d)-(f) MXD, and (g)-(i) OCN soundings, for the whole data range, as well as each season per category, and the combined average. Note that some seasonal data are not presented for each category (summer for CNT, winter for MXD and OCN, and spring for OCN), due to the small number of sounding data ( $<5 \%$ of the total number per category). 

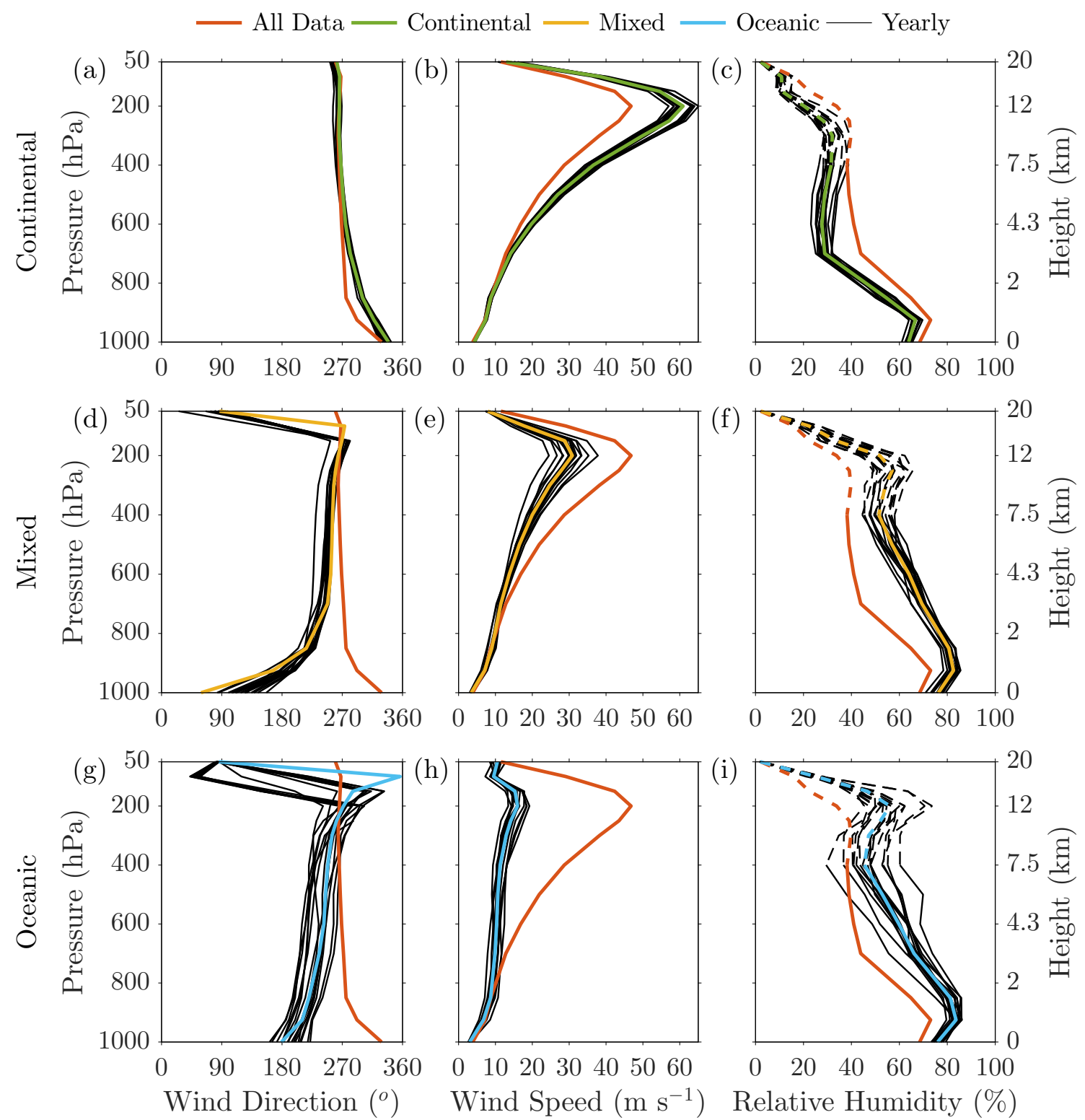

Figure 7: As Fig. 6 but with individual years from 1998-2013, and the combined average. 

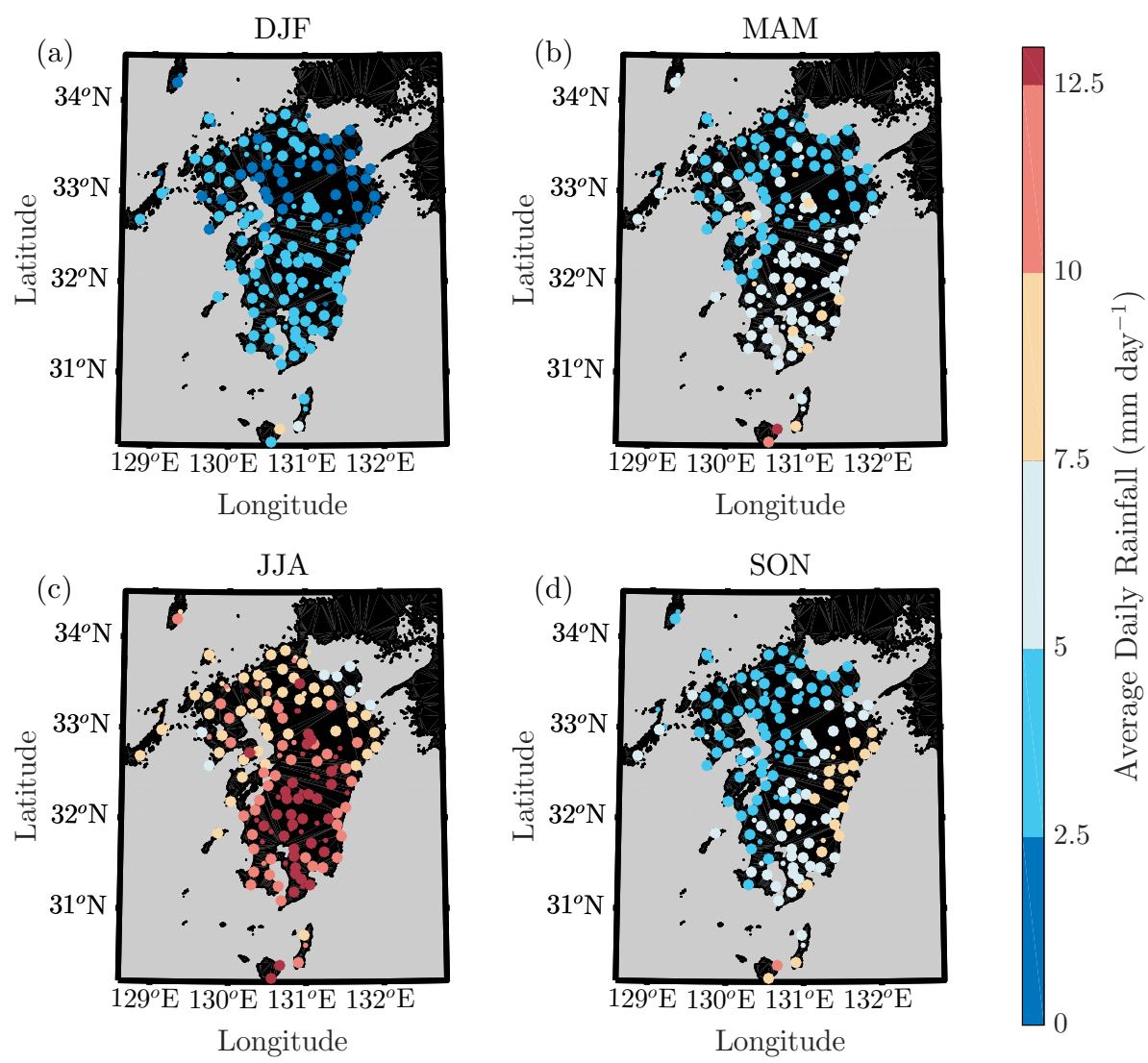

Figure 8: Combined average of daily rainfall over Kyushu for: (a) Winter, (b) Spring, (c) Summer, and (d) Autumn, for all days from 1998-2013. Based on a subset of days with the same sounding category for 0900 and 2100 JST, over both Kagoshima and Fukuoka ("concurrent"). Small dots signify statistically "compromised" stations (provide data for less that $90 \%$ of the study period). 

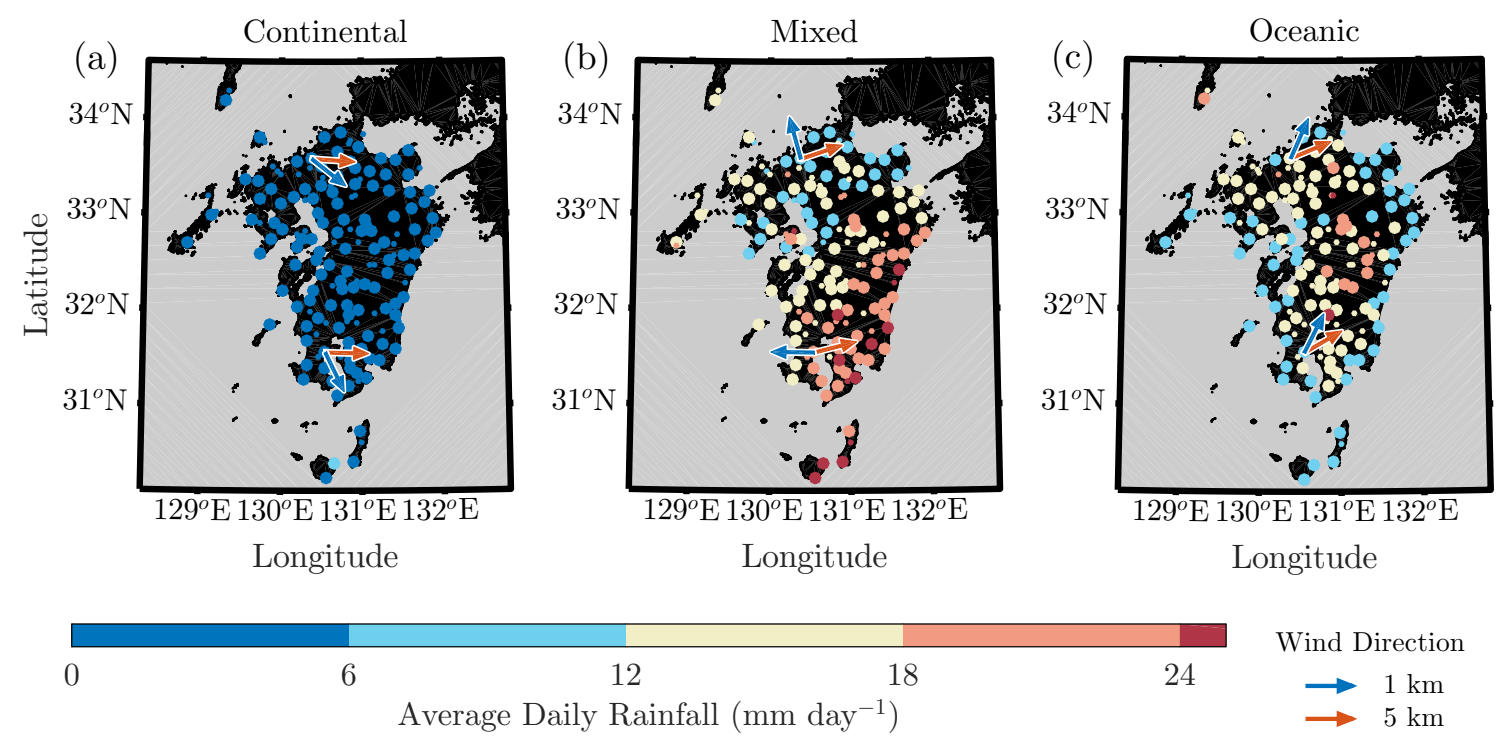

Figure 9: Average daily rainfall over Kyushu for: (a) CNT, (b) MXD, and (c) OCN. Arrows indicate average wind direction at 5 and $1 \mathrm{~km}$ over each station. Small dots signify statistically "compromised" stations (provide data for less that $90 \%$ of the study period). 

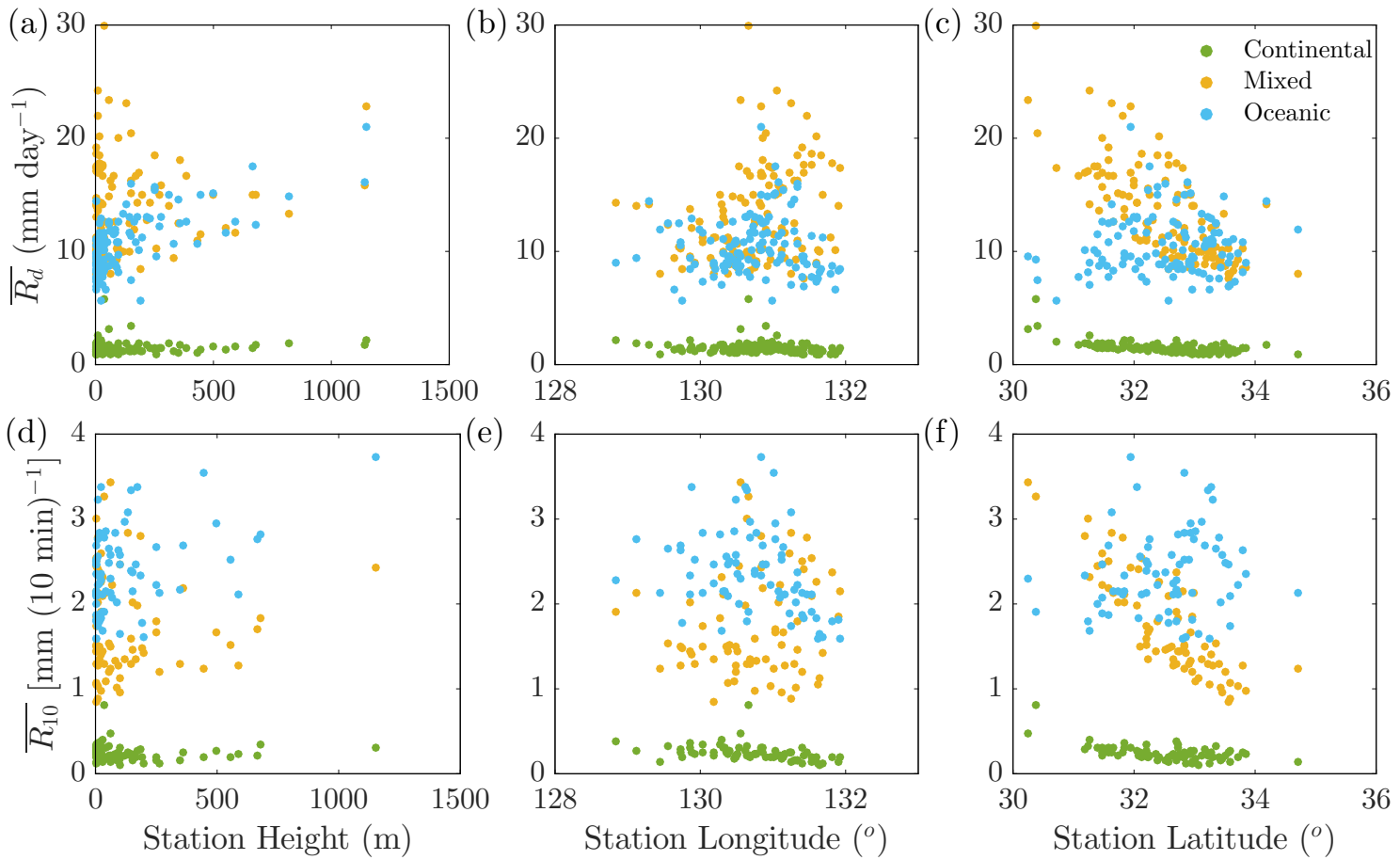

Figure 10: Scatter plots of average daily rainfall (Panels a-c) and peak rainfall intensity (Panels df) against: (a,d) Station height, (b,e) Station longitude, and (c,f) Station latitude, for all sounding categories for the "concurrent" days subset. Only statistically significant data are shown. 

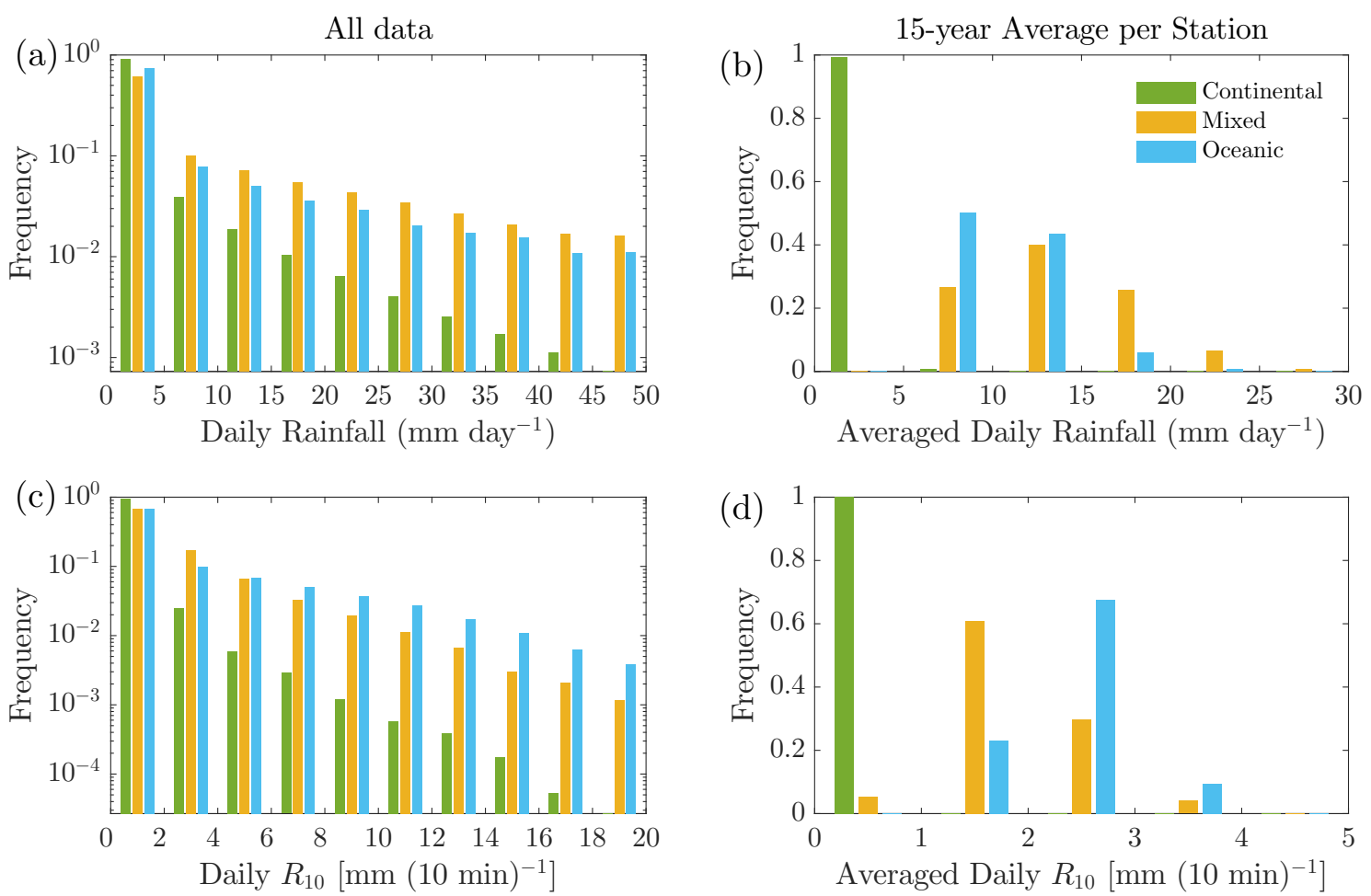

Figure 11: Histograms for: (a,b) Daily rainfall and $(\mathrm{c}, \mathrm{d})$ Peak rainfall intensity, for all sounding categories in the "concurrent" days subset. Panels a and c use all available daily data without any averaging (714240 data points in total), while panels b and d use the 16-year averages for every station (120 data points). Only statistically significant data are used for the calculations. Note the logarithmic scale in Panels a and c. 


\section{${ }_{704} 9$ Tables}

Table 1: Total number $(N)$ and frequency of occurrence $(f)$ for each sounding category. "UNC" stands for unclassifiable. In the last row, the values outside of the brackets are with respect to the total number of "concurrent" soundings, while the values in the brackets are with respect to the total number of soundings.

\begin{tabular}{cccccccccc}
\hline \hline Station & Total & $N_{C N T}$ & $f_{C N T}$ & $N_{M X D}$ & $f_{M X D}$ & $N_{O C N}$ & $f_{O C N}$ & $N_{U N C}$ & $f_{U N C}$ \\
\hline Kagoshima & 11688 & 6272 & 0.54 & 2448 & 0.21 & 2278 & 0.19 & 690 & 0.06 \\
Fukuoka & 11688 & 7162 & 0.56 & 2278 & 0.20 & 1583 & 0.14 & 656 & 0.06 \\
Total & 23376 & 13434 & 0.57 & 4735 & 0.20 & 3861 & 0.16 & 1346 & 0.06 \\
Concurrent & 3106 & 2231 & 0.72 & 490 & 0.16 & 385 & 0.12 & $105(8582)$ & $0.03(0.73)$ \\
\hline \hline
\end{tabular}


Table 2: CNT (first row), MXD (second row), OCN (third row), and all sounding (fourth row, bold) mean atmospheric soundings (1998-2013). Data in italics are estimates based on the ECMWF ERA-Interim reanalysis dataset.

\begin{tabular}{|c|c|c|c|c|c|c|c|}
\hline$P(\mathrm{hPa})$ & $Z(\mathrm{~m})$ & $T\left({ }^{\circ} \mathrm{C}\right)$ & $q\left(\mathrm{~g} \mathrm{~kg}^{-1}\right)$ & $\mathrm{RH}(\%)$ & $\theta(\mathrm{K})$ & $U\left(\mathrm{~m} \mathrm{~s}^{-1}\right)$ & $\mathrm{WD}\left({ }^{\circ}\right)$ \\
\hline \multirow[t]{4}{*}{50} & 20541 & -61.7 & 0.004 & 2.2 & 497.7 & 13.0 & 262 \\
\hline & 20767 & -61.8 & 0.004 & 2.4 & 497.5 & 7.9 & 87 \\
\hline & 20879 & -61.0 & 0.004 & 2.0 & 499.2 & 10.5 & 86 \\
\hline & 20646 & -61.6 & 0.004 & 2.1 & 498.0 & 11.5 & 260 \\
\hline \multirow[t]{4}{*}{100} & 16338 & -67.7 & 0.003 & 10.9 & 396.7 & 38.4 & 266 \\
\hline & 16606 & -71.7 & 0.004 & 22.3 & 388.9 & 17.8 & 274 \\
\hline & 16707 & -72.3 & 0.005 & 25.2 & 387.7 & 9.5 & 356 \\
\hline & 16456 & -69.3 & 0.004 & 16.0 & 393.6 & 29.1 & 268 \\
\hline \multirow[t]{4}{*}{150} & 13860 & -60.2 & 0.01 & 11.0 & 366.2 & 54.6 & 266 \\
\hline & 14175 & -63.4 & 0.01 & 33.6 & 360.6 & 28.8 & 269 \\
\hline & 14287 & -63.9 & 0.02 & 46.6 & 359.7 & 15.3 & 286 \\
\hline & 13998 & -61.5 & 0.01 & 22.5 & 364.0 & 42.4 & 267 \\
\hline \multirow[t]{4}{*}{200} & 12034 & -52.5 & 0.02 & 20.3 & 349.5 & 60.9 & 266 \\
\hline & 12364 & -52.2 & 0.08 & 51.8 & 349.9 & 30.9 & 264 \\
\hline & 12474 & -51.0 & 0.10 & 56.1 & 351.8 & 16.0 & 272 \\
\hline & 12178 & -52.2 & 0.05 & 33.8 & 350.0 & 46.8 & 266 \\
\hline \multirow[t]{4}{*}{250} & 10570 & -45.4 & 0.07 & 28.3 & 338.5 & 57.1 & 265 \\
\hline & 10885 & -41.2 & 0.24 & 57.00 & 344.7 & 27.9 & 260 \\
\hline & 10984 & -39.2 & 0.27 & 52.1 & 347.6 & 14.2 & 261 \\
\hline & 10706 & -43.5 & 0.15 & 39.2 & 341.3 & 43.5 & 264 \\
\hline \multirow[t]{4}{*}{300} & 9337 & -38.8 & 0.16 & 32.0 & 330.6 & 50.0 & 265 \\
\hline & 9621 & -31.6 & 0.51 & 54.2 & 340.7 & 24.7 & 257 \\
\hline & 9709 & -29.5 & 0.53 & 47.2 & 343.7 & 12.9 & 255 \\
\hline & 9459 & -35.7 & 0.31 & 39.8 & 334.9 & 38.2 & 264 \\
\hline \multirow[t]{4}{*}{400} & 7312 & -26.6 & 0.40 & 31.5 & 320.3 & 36.6 & 268 \\
\hline & 7523 & -17.0 & 1.33 & 51.4 & 332.8 & 20.0 & 256 \\
\hline & 7593 & -15.0 & 1.37 & 45.4 & 335.4 & 11.3 & 248 \\
\hline & 7404 & -22.6 & 0.77 & 38.2 & 325.6 & 28.7 & 265 \\
\hline \multirow[t]{4}{*}{500} & 5667 & -16.2 & 0.68 & 28.8 & 313.2 & 26.9 & 271 \\
\hline & 5813 & -6.7 & 2.61 & 56.9 & 324.8 & 16.5 & 254 \\
\hline & 5872 & -5.0 & 2.77 & 52.9 & 326.9 & 10.7 & 245 \\
\hline & 5732 & -12.3 & 1.45 & 39.0 & 318.0 & 21.9 & 267 \\
\hline \multirow[t]{4}{*}{600} & 4281 & -8.1 & 0.98 & 27.7 & 306.8 & 19.8 & 275 \\
\hline & 4374 & 1.0 & 4.31 & 64.0 & 317.3 & 13.8 & 253 \\
\hline & 4421 & 3.0 & 4.72 & 59.8 & 319.7 & 10.3 & 242 \\
\hline & 4324 & -4.4 & 2.33 & 41.0 & 311.2 & 16.9 & 269 \\
\hline \multirow[t]{4}{*}{700} & 3061 & -1.8 & 1.37 & 28.9 & 300.4 & 14.1 & 282 \\
\hline & 3111 & 7.4 & 6.29 & 69.4 & 310.7 & 11.5 & 248 \\
\hline & 3148 & 10.1 & 7.27 & 66.1 & 313.6 & 10.7 & 236 \\
\hline & 3086 & 2.1 & 3.43 & 43.9 & 304.8 & 12.8 & 272 \\
\hline \multirow[t]{4}{*}{850} & 1499 & 4.2 & 3.34 & 54.6 & 290.6 & 8.7 & 300 \\
\hline & 1487 & 14.7 & 10.10 & 80.6 & 301.6 & 9.0 & 216 \\
\hline & 1505 & 18.2 & 12.68 & 81.3 & 305.2 & 8.7 & 220 \\
\hline & 1497 & 8.8 & 6.37 & 64.8 & 295.4 & 8.8 & 276 \\
\hline \multirow[t]{4}{*}{925} & 806 & 7.8 & 5.05 & 66.7 & 287.3 & 7.4 & 317 \\
\hline & 765 & 18.0 & 11.81 & 82.6 & 297.7 & 7.1 & 167 \\
\hline & 773 & 22.1 & 15.41 & 83.6 & 301.9 & 6.8 & 210 \\
\hline & 792 & 12.4 & 8.26 & 73.1 & 292.0 & 7.2 & 292 \\
\hline \multirow[t]{4}{*}{1000} & 158 & 11.9 & 6.07 & 63.8 & 285.1 & 4.3 & 339 \\
\hline & 98 & 21.9 & 12.91 & 76.3 & 295.1 & 3.5 & 59 \\
\hline & 88 & 26.9 & 17.27 & 76.0 & 300.1 & 3.0 & 179 \\
\hline & 132 & 16.5 & 9.35 & 68.5 & 289.7 & 3.9 & 345 \\
\hline
\end{tabular}


Table 3: Surface and layer mean (850-500 hPa) sounding parameters for CNT (first row), MXD (second row), OCN (third row), and combined average (fourth row, bold).

\begin{tabular}{ccccccc}
\hline \hline$P(\mathrm{hPa})$ & $T\left({ }^{\circ} \mathrm{C}\right)$ & $q\left(\mathrm{~g} \mathrm{~kg}^{-1}\right)$ & $\mathrm{RH}(\%)$ & $\theta(\mathrm{K})$ & $U\left(\mathrm{~m} \mathrm{~s}^{-1}\right)$ & $\mathrm{WD}\left({ }^{\circ}\right)$ \\
\hline 1016 & 12.9 & 6.38 & 64.1 & 284.8 & 2.7 & 340 \\
1008 & 22.9 & 13.41 & 75.5 & 295.3 & 2.7 & 37 \\
1007 & 27.8 & 17.86 & 75.2 & 300.3 & 2.5 & 168 \\
$\mathbf{9 9 5}$ & $\mathbf{1 6 . 8}$ & $\mathbf{9 . 6 7}$ & $\mathbf{6 7 . 6}$ & $\mathbf{2 8 6 . 5}$ & $\mathbf{2 . 7}$ & $\mathbf{3 4 5}$ \\
$850-500$ mean & -5.5 & 1.59 & 35.0 & 302.7 & 17.4 & 282 \\
& 4.1 & 5.82 & 67.8 & 313.6 & 12.7 & 243 \\
& 6.6 & 9.86 & 65.0 & 316.3 & 9.89 & 236 \\
& $\mathbf{- 1 . 4}$ & $\mathbf{3 . 3 9}$ & $\mathbf{4 7 . 2}$ & $\mathbf{3 0 7 . 3}$ & $\mathbf{1 5 . 1}$ & $\mathbf{2 6 9}$ \\
\hline \hline
\end{tabular}


Table 4: Averages of stability, moisture indices, and rainfall for the CNT, MXD, OCN, and combined average for all sounding categories in the "concurrent" days subset. Rainfall-related values outside of brackets are calculated using all data, while values in brackets are calculated excluding rainfall values less that $1 \mathrm{~mm}$ day $^{-1}$ or $0.1 \mathrm{~mm}(10 \mathrm{~min})^{-1}$.

\begin{tabular}{|c|c|c|c|c|c|c|c|}
\hline & $\begin{array}{l}\mathrm{LCL} \\
(\mathrm{hPa})\end{array}$ & $\begin{array}{c}\text { CAPE } \\
\left(\mathrm{J} \mathrm{kg}^{-1}\right)\end{array}$ & $\begin{array}{c}\mathrm{CIN} \\
\left(\mathrm{J} \mathrm{kg}^{-1}\right)\end{array}$ & LI & $\begin{array}{l}\mathrm{PW} \\
(\mathrm{mm})\end{array}$ & $\begin{array}{c}\overline{R_{d}} \\
\left(\mathrm{~mm} \mathrm{day}^{-1}\right)\end{array}$ & $\begin{array}{c}\overline{R_{10}} \\
{\left[\mathrm{~mm}(10 \mathrm{~min})^{-1}\right]}\end{array}$ \\
\hline $\mathrm{CNT}$ & 891.0 & 5 & -43 & 11.8 & 14.5 & $1.33(1.48)$ & $0.23(0.26)$ \\
\hline MXD & 923.8 & 13 & -110 & 3.8 & 43.1 & $14.79(22.70)$ & $1.95(2.69)$ \\
\hline $\mathrm{OCN}$ & 924.7 & 581 & -61 & -1.9 & 52.8 & $13.00(23.81)$ & $2.69(4.72)$ \\
\hline ALL & 904.4 & 105 & -65 & 7.7 & 27.5 & $8.42(8.59)$ & $1.45(1.46)$ \\
\hline
\end{tabular}

